\title{
Electronic Monitoring Systems for Hand Hygiene: Systematic Review of Technology
}

Chaofan Wang, BSc, MSc; Weiwei Jiang, BSc, MSc; Kangning Yang, BSc, MSc; Difeng Yu, BSc; Joshua Newn, BSc, MSc, PhD; Zhanna Sarsenbayeva, BSc, MSc, PhD; Jorge Goncalves, BSc, MSc, PhD; Vassilis Kostakos, BSc, $\mathrm{PhD}$

School of Computing and Information Systems, The University of Melbourne, Carlton, Australia

Corresponding Author:

Chaofan Wang, BSc, MSc

School of Computing and Information Systems

The University of Melbourne

700 Swanston Street

Carlton, 3053

Australia

Phone: 61390358966

Email: chaofanw@student.unimelb.edu.au

\section{Abstract}

Background: Hand hygiene is one of the most effective ways of preventing health care-associated infections and reducing their transmission. Owing to recent advances in sensing technologies, electronic hand hygiene monitoring systems have been integrated into the daily routines of health care workers to measure their hand hygiene compliance and quality.

Objective: This review aims to summarize the latest technologies adopted in electronic hand hygiene monitoring systems and discuss the capabilities and limitations of these systems.

Methods: A systematic search of PubMed, ACM Digital Library, and IEEE Xplore Digital Library was performed following the PRISMA (Preferred Reporting Items for Systematic Reviews and Meta-Analyses) guidelines. Studies were initially screened and assessed independently by the 2 authors, and disagreements between them were further summarized and resolved by discussion with the senior author.

Results: In total, 1035 publications were retrieved by the search queries; of the 1035 papers, $89(8.60 \%)$ fulfilled the eligibility criteria and were retained for review. In summary, 73 studies used electronic monitoring systems to monitor hand hygiene compliance, including application-assisted direct observation (5/73, 7\%), camera-assisted observation (10/73, 14\%), sensor-assisted observation $(29 / 73,40 \%)$, and real-time locating system $(32 / 73,44 \%)$. A total of 21 studies evaluated hand hygiene quality, consisting of compliance with the World Health Organization 6-step hand hygiene techniques $(14 / 21,67 \%)$ and surface coverage or illumination reduction of fluorescent substances $(7 / 21,33 \%)$.

Conclusions: Electronic hand hygiene monitoring systems face issues of accuracy, data integration, privacy and confidentiality, usability, associated costs, and infrastructure improvements. Moreover, this review found that standardized measurement tools to evaluate system performance are lacking; thus, future research is needed to establish standardized metrics to measure system performance differences among electronic hand hygiene monitoring systems. Furthermore, with sensing technologies and algorithms continually advancing, more research is needed on their implementation to improve system performance and address other hand hygiene-related issues.

(J Med Internet Res 2021;23(11):e27880) doi: $\underline{10.2196 / 27880}$

\section{KEYWORDS}

hand hygiene; hand hygiene compliance; hand hygiene quality; electronic monitoring systems; systematic review; mobile phone 


\section{Introduction}

\section{Background}

Hand hygiene is one of the most effective ways of reducing the transmission of pathogens that cause health care-associated infections (HAIs) [1-3]. HAIs are infections that people acquire in health care settings [4] and are the most crucial challenge to patient safety in health care [5]. HAIs dramatically increase patients' length of stay, costs, mortality, and morbidity worldwide [6,7]. Moreover, HAIs also impose a heavy financial burden on health care systems. Solely in the United States, the estimated annual costs range from US \$28 billion to US \$45 billion [8]. The hands of health care workers (HCWs) represent the main pathway of pathogen transmission during health care
[2], and Stone et al [9] estimated that at least one-third of HAIs can be prevented by achieving better hand hygiene in health care settings.

In 2009, the World Health Organization (WHO) issued the first WHO guidelines on hand hygiene in health care to provide a thorough review of evidence on hand hygiene in health care and specific recommendations to improve practices in health care settings [2]. In the guidelines, the WHO summarizes the five key moments when HCWs should ensure hand hygiene [2], as shown in Figure 1. The guidelines also recommend two standard hand hygiene techniques, handwash with soap and water for visibly soiled hands and hand rub with alcohol-based formulation for routine decontamination of hands [2], as shown in Figure 2.

Figure 1. The key moments when health care workers should perform hand hygiene. Source: World Health Organization: "My 5 Moments for Hand Hygiene" (with permission) [2].

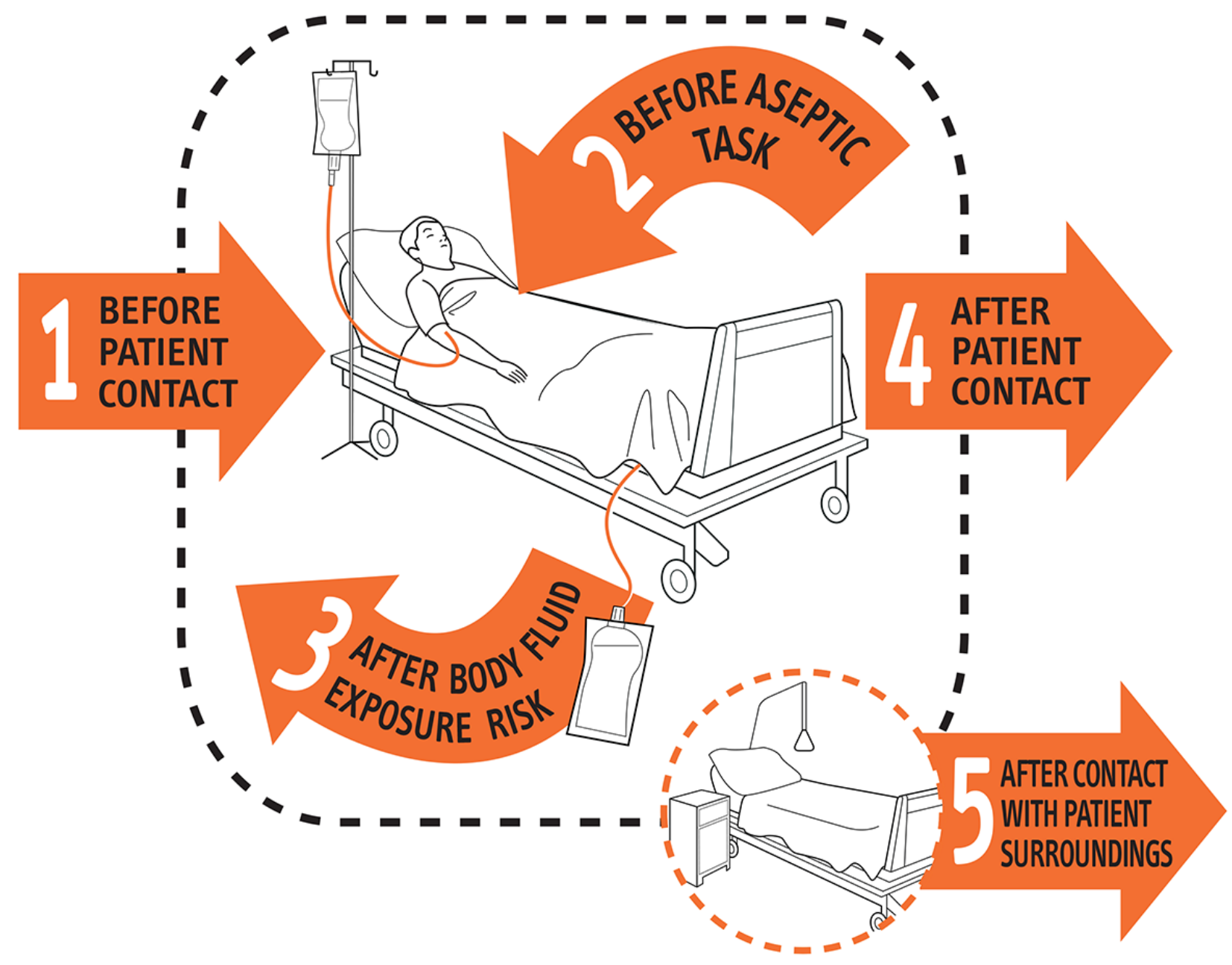


Figure 2. Standard World Health Organization procedures of alcohol-based hand rub and handwash with soap and water. Source: World Health Organization. How to Hand rub?/How to Handwash? (with permission) [10].

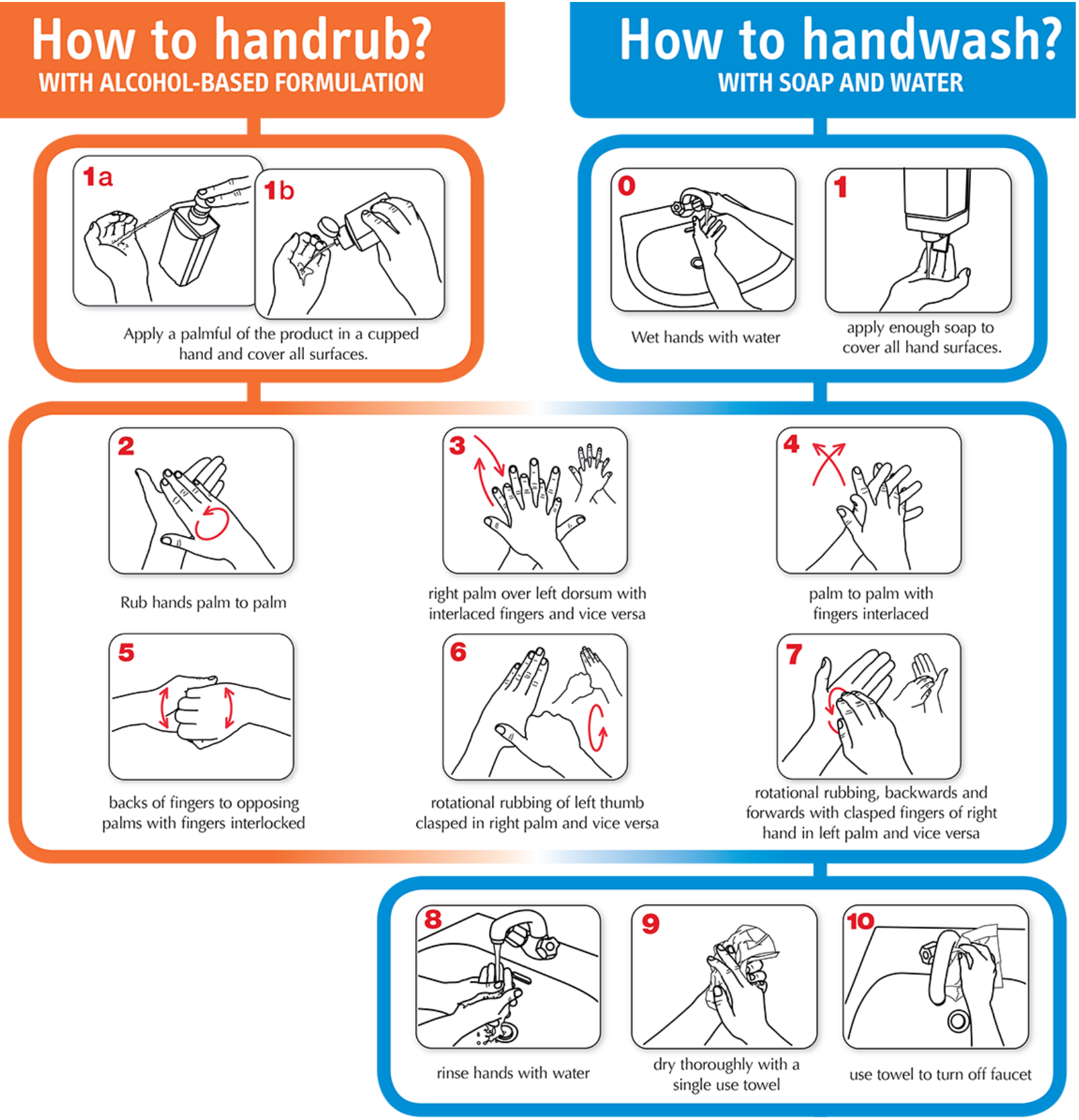

However, research has found that hand hygiene compliance is often poor [11,12]. By summarizing 96 empirical studies, Erasmus et al [12] reported that the median compliance rate was only $40 \%$ among HCWs. Meanwhile, research also found that hand hygiene quality was unsatisfactory [13-15]. Szilágyi et al [15] reported that only $72 \%$ of HCWs could adequately clean all hand surfaces immediately after hand hygiene training. Owing to the importance of hand hygiene, these findings suggest that monitoring hand hygiene practices and providing HCWs with feedback regarding their performance are essential to promote hand hygiene compliance and quality in health care settings [16].

Direct observation by trained auditors is considered the gold standard for monitoring hand hygiene compliance in health care settings [2,17]. Self-reporting by HCWs and the measurement of hand hygiene product consumption are also widely used to monitor hand hygiene compliance [18]. However, Boyce et al $[18,19]$ argued that the disadvantages of direct observation include time and resource consumption, insufficient sample size, lack of standardized observational practices, and the Hawthorne effect. Furthermore, self-reporting is not recommended by experts, as HCWs tend to overestimate their level of compliance, and the measurement of hand hygiene consumption cannot assess the appropriateness of HCWs' hand hygiene timing and quality [18].

To assess hand hygiene quality, previous studies have used direct observation by trained auditors to observe HCWs' compliance with the WHO 6-step hand hygiene technique 
$[13,14,20]$. Another common technique is using UV fluorescent substances to detect the surface coverage of hand hygiene products after hand hygiene $[21,22]$. Moreover, microbiological tests measure bacteria reduction count to evaluate hand hygiene quality $[21,23,24]$. However, using direct observation to monitor hand hygiene quality suffers from the same disadvantages as using direct observation to monitor hand hygiene compliance. Visual inspection of fluorescence is restricted to small sample sizes and a lack of standardized observational practices [25]. Furthermore, microbiological tests require time-consuming procedures and often overestimate the reduction of bacteria [21].

Given the above trade-offs, there has been increased interest in developing electronic monitoring systems to serve as an alternative or supplemental monitoring approach [19]. These electronic hand hygiene monitoring systems can be further categorized into electronic hand hygiene compliance monitoring systems and electronic hand hygiene quality monitoring systems.

Although previous reviews have described electronic hand hygiene compliance monitoring systems in detail, this is not the case for electronic hand hygiene quality monitoring systems $[19,26,27]$. Recent advances in sensor technologies and algorithms have also contributed to the development of new electronic hand hygiene monitoring systems. Furthermore, electronic hand hygiene monitoring systems have limitations that need to be identified and highlighted.

\section{Objectives}

This paper aims to (1) review the literature regarding the latest technological developments in electronic hand hygiene systems for monitoring compliance and quality and (2) summarize the limitations and challenges when developing and deploying such systems in health care settings.

\section{Methods}

\section{Search Strategy and Selection Criteria}

We conducted a bibliographic search of the following web-based databases: PubMed, ACM Digital Library, and IEEE Xplore Digital Library. This systematic review followed the PRISMA (Preferred Reporting Items for Systematic Reviews and Meta-Analyses) [28] guidelines to reduce the risk of bias and increase its transparency and replicability. This systematic review is not registered on the network, and its review protocol is described below.

We derived the search query using a combination of key terms from previously published literature and expert advice. For the health-related database (PubMed), we specified search terms regarding hand hygiene, technological innovation, and observation to target electronic hand hygiene monitoring systems. For the technological databases (ACM Digital Library and IEEE Xplore Digital Library), we specified terms related to hand hygiene to include relevant technical innovations. The search queries for each database are given in Multimedia Appendix 1. Papers published between January 1, 2000, and June 30, 2020, were included in this study. As older literature is less relevant to today's electronic hand hygiene monitoring systems, we decided to exclude it.
Studies were included if they (1) developed an electronic method or system to monitor hand hygiene compliance or hand hygiene quality, (2) used an existing electronic device or application to support hand hygiene monitoring, or (3) adopted an existing electronic hand hygiene monitoring system and provided sufficient technical details. Meanwhile, studies were excluded if they (1) did not explicitly target electronic hand hygiene monitoring, (2) did not provide adequate technical details (eg, communication protocol and sensor specification), (3) were not published in English, or (4) were not original research papers (eg, abstracts, review papers, and editorials).

To identify the relevant studies, we first imported the search results into a spreadsheet for duplicate removal. Then, the titles were screened based on the selection criteria. If a publication passed the title screening, its abstract was assessed. Finally, the decision for inclusion was made according to the full text of the study. A total of 2 authors, CW and WJ, independently performed the study selection procedure for the retrieved publications. Disagreements between the 2 authors were further summarized and resolved by discussion with the senior author, VK, whenever necessary.

\section{Data Extraction and Data Analysis}

To collect information from the included studies in a consistent manner, we created a data extraction table (Multimedia Appendix 2). A total of 2 authors, CW and WJ, independently performed the data extraction procedure, whereas disagreements were resolved by discussion with the senior author, VK.

As we aimed to summarize the different technologies used in electronic hand hygiene monitoring systems, we adopted a narrative approach to synthesize the extracted data. All studies were first grouped by their study aims (monitoring either hand hygiene compliance or quality). After that, the categorized studies were further divided into several categories according to their technical details. Specifically, electronic hand hygiene compliance monitoring systems include (1) application-assisted direct observation, (2) camera-assisted observation, (3) sensor-assisted observation, and (4) real-time locating systems (RTLSs). Meanwhile, electronic hand hygiene quality monitoring systems include (1) measure compliance with the WHO 6-step hand hygiene techniques and (2) detect surface coverage or illumination reduction of fluorescent substances.

Owing to the high level of heterogeneity of the included studies, this study could not provide meta-analyses of the system performance and relevant HCWs' behavior changes. The significant heterogeneity also resulted in missing standardized automation tools to evaluate the risk of bias and assess the certainty for each included study.

\section{Results}

\section{Inclusion of Studies and Study Characteristics}

In total, 1035 publications were retrieved by the initial search queries (777/1035, 75.07\% from PubMed; 190/1035, 18.36\% from the IEEE Xplore Digital Library, and; 68/1035, 6.57\% from the ACM Digital Library). None of the retrieved studies were removed based on duplication. After screening the titles and abstracts, $79.42 \%(822 / 1035)$ of studies were excluded for 
not meeting the eligibility criteria. Thus, $20.58 \%$ (213/1035) of studies were reviewed for the full text. Of these 213 studies, $124(58.2 \%)$ studies were excluded. The main reasons for exclusion were the irrelevance of electronic hand hygiene monitoring systems $(59 / 124,47.6 \%)$ and insufficient technical

Figure 3. Flowchart of the selection process for the systematic review.

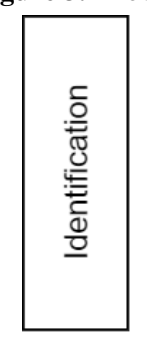

Articles identified through database search $(\mathrm{N}=1035)$

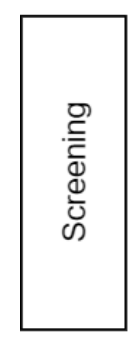

Articles after duplicates removed $(\mathrm{N}=1035)$
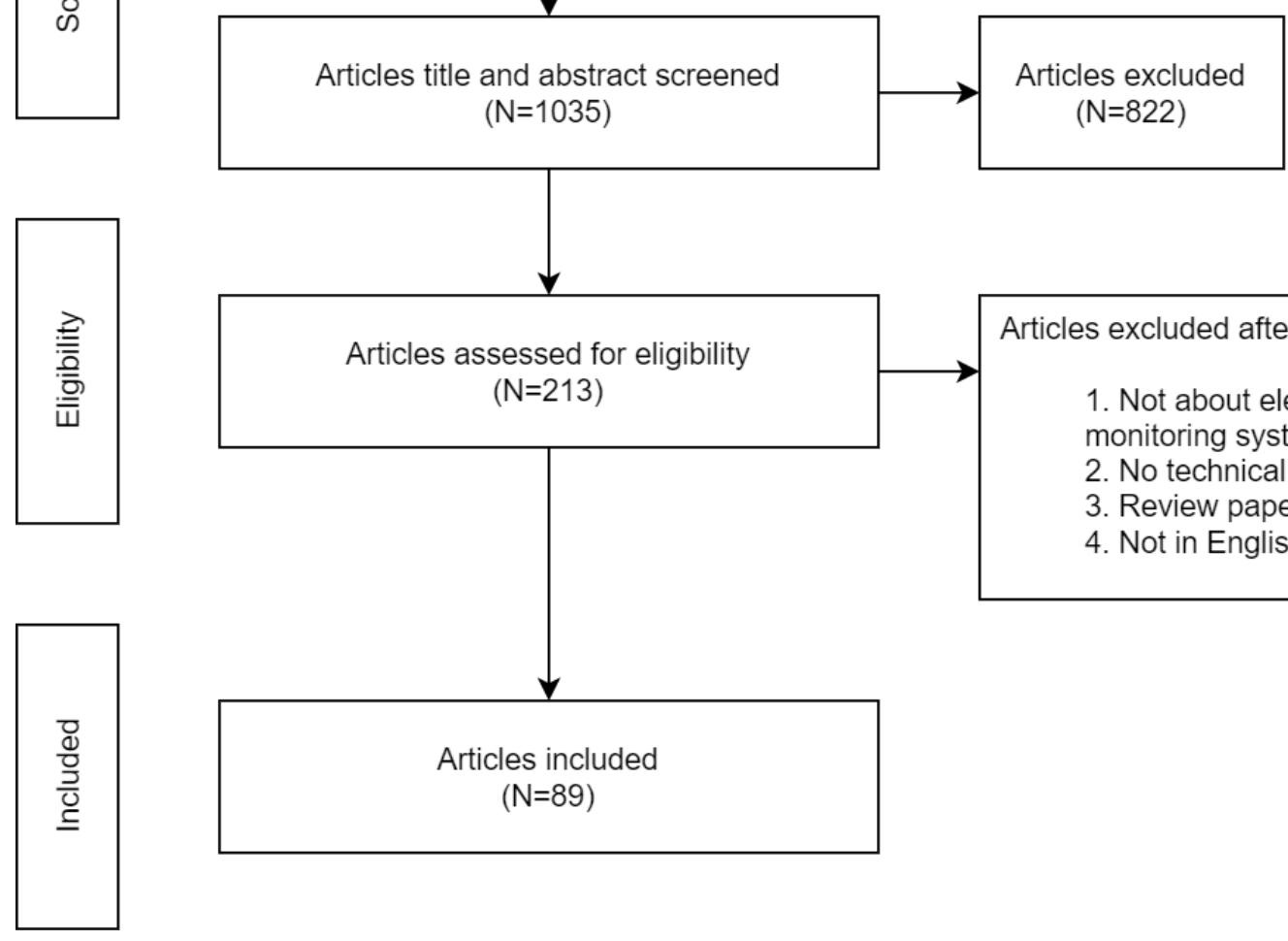

All the 89 reviewed studies were published between 2009 and 2020, with $9(10 \%)$ dated in or before 2010 [42,46,56,60,81,83,86,92,113], $38(43 \%)$ dated between 2011 and $2015[32,33,36,38,39,45,48,49,51,52,54,59,61,63-65,67$, $68,72,73,78-80,82,84,87-89,93-97,99-101,108,116]$, and 42 $(47 \%)$ dated in or after $2016[25,29-31,34,35,37,40,41$, $43,44,47,50,53,55,57,58,62,66,69-71,74-77,85,90,91$, $98,102-107,109-112,114,115]$. Regarding the countries where the studies were conducted, 6 countries had $\geq 5$ studies: United States $(31 / 89,35 \%) \quad[25,30,31,36,38,39,41,46-48,51,52,59$, 61,63,68, 69,71,74,76,80-84,92,95,96,101,107,111], Canada $(8 / 89,9 \%) \quad[42,72,86-89,98,100]$, Japan (7/89, 8\%) [44,45,55,58,62,114,115], Brazil (6/89, 7\%) [32,33,49,56,67,78], Germany $(6 / 89,7 \%)[37,40,50,66,108,109]$, and India $(5 / 89$, details $(35 / 124,28.2 \%)$. No study was excluded if they met the inclusion criteria. Therefore, of the 213 studies, 89 (41.8\%) fulfilled the eligibility criteria and were retained for review [25,29-116]. Figure 3 shows the process of searching for and selecting the studies included in the review.
$6 \%)[64,65,94,99,102]$. The demographic information of participants was provided in only $70 \%$ (62/89) of studies. Most studies $(50 / 89,56 \%)$ recruited HCWs from hospitals or clinics [29,30,32-40,44,46-57,59,61,66-68,73-75,77-80, $82,84,86,87,89-91,95,96,98-100,103,106]$, and few $(2 / 89,2 \%)$ studies also involved patients from hospitals [66,94]. The remaining studies recruited the general public $(7 / 89,8 \%)$ $[45,60,64,65,109-111]$ or students $(4 / 89,4 \%)[76,104,114,115]$ from communities or educational settings.

\section{Compliance Monitoring Systems}

We identified 73 studies that either implemented or adopted an electronic monitoring system for hand hygiene compliance and grouped them into 4 categories based on their enabling 
technology [19,26]: application-assisted direct observation (5/73, $7 \%)$, camera-assisted observation $(10 / 73,14 \%)$, sensor-assisted observation $(29 / 73,40 \%)$, and RTLS $(32 / 73,44 \%)$.

\section{Application-Assisted Direct Observation}

Approximately 7\% (5/73) of studies used applications to assist trained auditors in observing hand hygiene compliance (details are included in Table 1) [29-33]. With these applications, human observers could record their observations using smartphones or tablets. Unlike manual observation with paper forms, application-assisted observation avoids the need for transcription, which could cause delays in analysis, increase the associated cost, and introduce errors [117]. In addition, the prevalence of smartphones and tablets in health care settings makes data collection more unobtrusive and reduces the Hawthorne effect [26]. Both in-house and commercial applications have been used for application-assisted direct observations.

The monitored hand hygiene opportunities may vary in different studies. Most studies followed the instructions given by the WHO 5 moments for hand hygiene [29,31-33]. Conversely, Sickbert-Bennett et al [30] simplified the observation process to patient room entry or exit events (as proxies for moments 1 , 4 , and 5).

Table 1. Description of application-assisted direct observation studies.

\begin{tabular}{|c|c|c|c|}
\hline Paper and system description & Required device & System type & $\begin{array}{l}\text { System metrics (hand hy- } \\
\text { giene opportunities) }\end{array}$ \\
\hline \multicolumn{4}{|l|}{ Kariyawasam et al [29] } \\
\hline Self-developed application & Android tablet & Research & $\mathrm{WHO}^{\mathrm{a}} 5$ moments \\
\hline \multicolumn{4}{|c|}{ Magnus et al [32] and Sodré da Costa et al [33] } \\
\hline iScrub & iOS devices & Commercial & WHO 5 moments \\
\hline \multicolumn{4}{|l|}{ Sickbert-Bennett et al [30] } \\
\hline iScrub & iOS devices & Commercial & $\begin{array}{l}\text { Patient room entry/exit } \\
\text { events }\end{array}$ \\
\hline SelectSurvey & Web browser & Commercial & $\begin{array}{l}\text { Patient room entry/exit } \\
\text { events }\end{array}$ \\
\hline \multicolumn{4}{|l|}{ Wiemken et al [31] } \\
\hline Google forms & Web browser & Commercial & WHO 5 moments \\
\hline
\end{tabular}

${ }^{\mathrm{a}}$ WHO: World Health Organization.

\section{Camera-Assisted Observation}

In contrast with application-assisted direct observation, which solely relies on human auditors, studies with camera-assisted observation could rely on either human auditors [34-40] or algorithms [41-43] for analysis (details included in Table 2). Approximately $30 \%$ (3/10) of studies installed cameras inside and outside patient rooms to capture all five hand hygiene moments [34-36]. Researchers manually coded the streaming and recorded videos. Armellino et al $[38,39]$ recruited a remote video auditing company (Arrowsight, Inc) to conduct compliance observations only when HCWs entered or exited the patient room (as proxies for moments 1, 4, and 5). Rather than installing cameras in the environment, Diefenbacher et al $[37,40]$ proposed mounting a camera on the chest of HCWs that aimed at their hands, and researchers further analyzed these first-person view video recordings according to the WHO 5 moments for hand hygiene.

In terms of automated analyses, Zhong et al [41] attached a red green blue (RGB) camera to the chest of HCWs to collect egocentric videos. By feeding RGB images and optical flow images inside a two-stream convolutional neural network, they identified hand hygiene events in HCWs' daily routines [41]. Snoek et al [42] used an RGB camera with a microphone to observe handwash events in older adults with Alzheimer disease. Awwad et al [43] used an RGB-depth camera, Kinect (Microsoft Corporation), to achieve automatic detection of moment 1 (before touching a patient). Depth cameras generate pictures with stereo information, and these pictures have pixels with a value being the distance from the camera or depth. Hand hygiene compliance of moment 1 was then estimated by measuring the proximity between the subjects' hands and patient/bed with the presence of hand rub events [43]. 
Table 2. Description of camera-assisted observation studies.

\begin{tabular}{|c|c|c|c|c|}
\hline Paper and system description & Device location & Video type & System type & $\begin{array}{l}\text { System metrics (hand hy- } \\
\text { giene opportunities) }\end{array}$ \\
\hline \multicolumn{5}{|l|}{ Auditor (human) } \\
\hline \multicolumn{5}{|l|}{ Brotfain et al [34] } \\
\hline $\mathrm{RGB}^{\mathrm{a}}$ camera & Patient room & Streaming & Research & $\mathrm{WHO}^{\mathrm{b}} 5$ moments \\
\hline \multicolumn{5}{|l|}{ Sánchez-Carrillo et al [35] } \\
\hline RGB camera & Patient room & Recorded & Research & WHO 5 moments \\
\hline \multicolumn{5}{|l|}{ Diller et al [36] } \\
\hline RGB camera (with infrared lens) & Patient room & Recorded & Research & WHO 5 moments \\
\hline \multicolumn{5}{|l|}{ Armellino et al $[38,39]$} \\
\hline RGB camera & $\begin{array}{l}\text { Sink and sanitizer } \\
\text { dispenser }\end{array}$ & Recorded & $\begin{array}{l}\text { Commercial (Ar- } \\
\text { rowsight) }\end{array}$ & $\begin{array}{l}\text { Patient room entry/exit } \\
\text { events }\end{array}$ \\
\hline Motion sensor & $\begin{array}{l}\text { Patient room en- } \\
\text { trance }\end{array}$ & Recorded & $\begin{array}{l}\text { Commercial (Ar- } \\
\text { rowsight) }\end{array}$ & $\begin{array}{l}\text { Patient room entry/exit } \\
\text { events }\end{array}$ \\
\hline \multicolumn{5}{|l|}{ Diefenbacher et al $[37,40]$} \\
\hline RGB camera & $\mathrm{HCWs}^{\mathrm{c}}$ (chest) & Recorded & Research & WHO 5 moments \\
\hline \multicolumn{5}{|l|}{ Auditor (algorithm) } \\
\hline \multicolumn{5}{|l|}{ Zhong et al [41] } \\
\hline RGB camera & HCWs (chest) & Recorded & Research & Hand hygiene events \\
\hline \multicolumn{5}{|l|}{ Snoek et al [42] } \\
\hline RGB camera & Sink & Recorded & Research & $\begin{array}{l}\text { Hand hygiene events ( } 5 \\
\text { states related to faucet in- } \\
\text { teraction) }\end{array}$ \\
\hline Microphone & Sink & Recorded & Research & $\begin{array}{l}\text { Hand hygiene events ( } 5 \\
\text { states related to faucet in- } \\
\text { teraction) }\end{array}$ \\
\hline \multicolumn{5}{|l|}{ Awwad et al [43] } \\
\hline RGB depth camera & Patient bed & Recorded & Research & $\begin{array}{l}\text { Moment } 1 \text { (before touch- } \\
\text { ing a patient) }\end{array}$ \\
\hline
\end{tabular}

${ }^{\mathrm{a}} \mathrm{RGB}$ : red green blue.

${ }^{b}$ WHO: World Health Organization.

${ }^{\mathrm{c}} \mathrm{HCW}$ : health care worker.

\section{Sensor-Assisted Observation}

Of the 73 studies, 29 (40\%) observed hand hygiene compliance using sensors (details are included in Table 3) [32,33,44-70]. These studies were grouped into 3 categories on the basis of sensor type: electronic dispenser, electronic dispenser assisted by other sensors, and inertial measurement unit (IMU) and microphone.

Of these 29 studies, 15 (52\%) used electronic dispensers to record the frequency of hand hygiene events and estimate the volume of hand hygiene products dispensed [32,33,44-50,54-57,59,67]. A range of sensors was used to trigger the electronic dispenser counter, including pressure resistors [45,53], magnetic sensors [66], and photosensors [58]. These records were then manually collected by researchers or wirelessly transmitted to the associated servers for further analysis. Compared with direct observation, electronic dispensers can capture hand hygiene events with substantially

fewer personnel resources and are unaffected by the Hawthorne effect [19]. However, electronic dispensers cannot detect the hand hygiene opportunities specified by the WHO 5 moments for hand hygiene [19]. Thus, several studies supplemented hand hygiene events with further information to estimate hand hygiene compliance, including outpatient visit records, the expected number of hand hygiene events, ward-specific conversion factors, the number of patients in the unit, nurse visit records, and documented activities [44,48-50,55,57,59].

As electronic dispensers cannot detect hand hygiene opportunities according to the WHO guidelines, other sensors were used to capture these opportunities [51-53,61,62,66,68]. A common practice was to use motion sensors to record patient room entry or exit events (as proxies for moments 1, 4, and 5) $[51,61,66]$. Here, the dispensers and motion sensors uploaded the time stamp of dispense and room entry/exit events to a server. Once a motion sensor was activated, the server measured 
the occurrence of a hand hygiene event within a predefined period and thus estimated the hand hygiene compliance rate. Conversely, Geilleit et al [53] placed a motion sensor around HCWs' working area and pressure plates on patient couches and chairs. Hand hygiene opportunities were defined as the movement of HCWs into a patient zone when the pressure plates were activated. Furthermore, studies used electronic dispensers with other sensors, including IMUs and microphones, to recognize different types of hand hygiene events from HCWs' daily routines $[52,62,68]$.

Of the 29 studies, 7 (24\%) used an IMU and microphone to distinguish hand hygiene events from daily activities [58,60,63-65,69,70]. An IMU is an electronic sensor that measures a body's specific force, angular rate, and orientation.
Of the 7 studies, 2 (29\%) attached an IMU wristband to users' wrists to collect physical signals and utilize these signals to recognize hand hygiene events [63,69]. By using acceleration, gyration, and audio signals from participants' wrists, Wijayasingha et al [70] applied the naive Bayes algorithm to identify both hand hygiene and oral hygiene events from people with developmental disabilities. Instead of placing sensors on users' wrists, $43 \%$ (3/7) of studies embedded IMU sensors with or without microphones inside soap bars $[60,64,65]$. These augmented soap bars were then distributed to low-income households to monitor their soap use associated with hand and body wash. Furthermore, Miyazaki et al [58] attached a microphone to a sink to distinguish hand hygiene events from other daily activities. 
Table 3. Description of sensor-assisted observation studies.

\begin{tabular}{|c|c|c|c|}
\hline Paper and system description & Device location & System type & $\begin{array}{l}\text { System metrics (hand hygiene oppor- } \\
\text { tunities) }\end{array}$ \\
\hline
\end{tabular}

\section{Electronic dispenser}

\section{Arai et al [44]}

Dispenser

Asai et al [45]

Dispenser

Boyce et al [46]

Dispenser

\section{Cohen et al [47]}

Dispenser

\section{Conway et al [48]}

Dispenser

Diefenbacher et al [50]

Dispenser

Helder et al [54]

Dispenser

Kato et al [55]

Dispenser

Morgan et al [59]

Dispenser

De MacEdo et al [49]

Dispenser

\section{Marra et al [56,67], Magnus et al [32], and Sodré da Costa et al [33]}

Dispenser

\section{Scheithauer et al [57]}

Dispenser

\section{Electronic dispenser assisted by other sensors}

Ellison et al [51]

Dispenser

Motion sensor

Sharma et al [61]

Dispenser

Motion sensor
Patient room

Patient room

Throughout entire facility

Throughout entire facility

Patient room

Patient room

Outpatient area

Patient room

N/A

Commercial (NXT 1-L model)

Commercial (Ingo-man Weco)

Commercial (ComSens NewCompliance)

Commercial (CARECOM Co, Ltd)

Commercial (NXT 1-L model)

Throughout entire facility

Throughout intensive care units

Patient room entrance

$\begin{array}{ll}\text { Hallway } & \text { Research } \\ \begin{array}{l}\text { Examination room } \\ \text { entrance }\end{array} & \text { Research }\end{array}$

Commercial (Ingo-man We- Documented activities co)

N/A

N/A Patient room entry/exit events

Patient room entry/exit events

Patient room entry/exit events

Patient room entry/exit events

Gaube et al [66] 


\begin{tabular}{|c|c|c|c|}
\hline Paper and system description & Device location & System type & $\begin{array}{l}\text { System metrics (hand hygiene oppor- } \\
\text { tunities) }\end{array}$ \\
\hline Dispenser & $\begin{array}{l}\text { Patient room and } \\
\text { hallway }\end{array}$ & Research & Patient room entry/exit events \\
\hline Motion sensor & Dispenser & Research & Patient room entry/exit events \\
\hline \multicolumn{4}{|l|}{ Geilleit et al [53] } \\
\hline Dispenser & Examination room & Research & Patient room entry/exit events \\
\hline Motion sensor & $\mathrm{HCWs}{ }^{\mathrm{b}}$ work area & Research & Patient room entry/exit events \\
\hline Pressure plate & $\begin{array}{l}\text { Examination couch, } \\
\text { Chair }\end{array}$ & Research & Patient room entry/exit events \\
\hline \multicolumn{4}{|l|}{ Galluzzi et al $[52,68]$} \\
\hline Dispenser & N/A & Research & Hand hygiene events \\
\hline $\mathrm{IMU}^{\mathrm{c}}$ & HCWs (wristwatch) & Research & Hand hygiene events \\
\hline \multicolumn{4}{|l|}{ Tobita et al [62] } \\
\hline Dispenser & Sink & Research & Hand hygiene events \\
\hline Microphone & Sink & Research & Hand hygiene events \\
\hline \multicolumn{4}{|l|}{ IMU and microphone } \\
\hline \multicolumn{4}{|l|}{ Uddin et al [63] } \\
\hline IMU & HCWs (wristband) & Research & Hand hygiene events \\
\hline \multicolumn{4}{|l|}{ Li et al [69] } \\
\hline IMU & HCWs (wristband) & Research & Hand hygiene events \\
\hline \multicolumn{4}{|l|}{ Ram et al [60] } \\
\hline IMU & Soap bar & Research & Hand hygiene events \\
\hline \multicolumn{4}{|c|}{ Wright et al [64] and Zillmer et al [65] } \\
\hline IMU & Soap bar & Research & Hand hygiene events \\
\hline Microphone & Soap bar & Research & Hand hygiene events \\
\hline \multicolumn{4}{|l|}{ Wijayasingha et al [70] } \\
\hline IMU & HCWs (wristwatch) & Research & Hand hygiene events \\
\hline Microphone & HCWs (wristwatch) & Research & Hand hygiene events \\
\hline \multicolumn{4}{|l|}{ Miyazaki et al [58] } \\
\hline Microphone & Sink & Research & Hand hygiene events \\
\hline
\end{tabular}

${ }^{\mathrm{a}} \mathrm{N} / \mathrm{A}$ : not applicable.

${ }^{\mathrm{b}} \mathrm{HCW}$ : health care worker.

${ }^{\mathrm{c}} \mathrm{IMU}$ : inertial measurement unit.

\section{Real-time Locating Systems}

Of the 73 studies, 32 (44\%) studies deployed RTLSs to track hand hygiene compliance (details included in Table 4) [67,71-101]. The RTLS was originally used to identify and track the location of objects or people in real time within a specified area. By sensing dispenser actuation and HCWs' movements, servers from an RTLS can measure HCWs' hand hygiene compliance rates as the ratio of dispenser actuation to the patient room or area entry or exit events (as proxies for moments 1, 4, and 5) [19]. On the basis of the underlying technology, we divided these systems into 6 categories: radio-frequency identification (RFID), infrared, ultrasound, Bluetooth low energy (BLE), IEEE 802.15.4/ZigBee, and Wi-Fi.
Of the 32 studies, $10(31 \%)$ developed or deployed an RFID-based RTLS [71,73,75,76,83,84,90,93,97,99]. RFID uses radio waves to identify and track tags attached to objects. RFID tags can come in a variety of shapes and can be embedded into HCWs' name tags, wristbands, bracelets, and even shoes. When HCWs with RFID tags pass RFID readers, the readers detect the HCWs' tags and then communicate the collected information to a central server. To record HCWs' hand hygiene events, $30 \%$ (3/10) of studies placed RFID readers either next to dispensers or embedded RFID readers into dispensers [71,76,93], and these RFID readers were activated by dispensing events. By installing RFID readers next to dispensers and at the entrance of patient rooms or around patient beds, RFID-based RTLS could recognize both hand hygiene events and the entry and exit of 
individuals into a patient room or a patient area $[73,75,83,84,90,99]$. Furthermore, several other sensors were used to assist in the observation of RFID-based RTLS, including motion sensors (recording movements around patient beds), IMUs (recording duration of hand hygiene events), and ethanol sensors (recognizing alcohol-based hand rub events) [90,97,99].

Of the 32 studies, 8 (25\%) studies adopted infrared-based RTLSs to monitor hand hygiene compliance $[72,74,77,86-89,98]$. An infrared transmitter uses infrared light pulses to transmit a unique infrared code to its receiver, and the receiver can then estimate their relative position inside a building. For all 8 studies, infrared transmitters were installed across health care settings and continuously emitted their relative location information (eg, patient room, patient bed, and hallway). In addition, the transmitters were embedded in dispensers and activated for a short period after dispenser actuation. The infrared receivers were carried by $\mathrm{HCW}$ and continuously received location information from the transmitter and counted HCWs' hand hygiene events. In addition, $63 \%$ (5/8) of studies used a wearable dispenser to facilitate HCWs' hand hygiene practices. Furthermore, an ethanol sensor was deployed in an infrared-based RTLS to recognize hand rub events rather than relying on a wall-mount dispenser [77].

Of the 32 studies, 2 (6\%) studies deployed ultrasound-based RTLSs [79,100]. Similar to other RTLS, ultrasound-based RTLSs comprise transmitters, receivers, and dispensers. Transmitters emit sound in the ultrasonic range, and receivers detect these sounds and thus locate the transmitters. Unlike infrared-based RTLSs, ultrasonic transmitters were typically either placed in health care settings or carried by HCWs, and thus the sound contained either location information or HCWs' identity. Through the collected signals, the receivers could locate the HCWs' real-time location and recognize patient room entry/exit events. When dispensers were used in ultrasound-based RTLSs, transmitters or receivers were also embedded in these dispensers and transmitted dispensing events to the receivers. 
Table 4. Description of real-time locating system studies.

\begin{tabular}{|c|c|c|c|}
\hline Paper and system description & Device location & System type & $\begin{array}{l}\text { System metrics (hand hygiene } \\
\text { opportunities) }\end{array}$ \\
\hline \multicolumn{4}{|c|}{ Radio-frequency identification (RFID) } \\
\hline \multicolumn{4}{|l|}{ Decker et al [76] } \\
\hline RFID tag & $\mathrm{HCWs}^{\mathrm{a}}(\mathrm{tag})$ & Research & Class schedules \\
\hline RFID reader & Dispenser & Research & Class schedules \\
\hline \multicolumn{4}{|l|}{ Bal et al [71] } \\
\hline RFID tag & HCWs (tag) & Research & Hand hygiene events \\
\hline RFID reader & Dispenser and faucet & Research & Hand hygiene events \\
\hline Dispenser/faucet & Patient room entrance and patient bed & Research & Hand hygiene events \\
\hline \multicolumn{4}{|l|}{ Meydanci et al [93] } \\
\hline RFID tag & HCWs (wristband) & Research & Hand hygiene events \\
\hline RFID reader & Dispenser & Research & Hand hygiene events \\
\hline Dispenser & Patient room and hallway & Research & Hand hygiene events \\
\hline \multicolumn{4}{|c|}{ Boudjema et al [73] and Brouqui et al [75] } \\
\hline RFID tag & HCWs (shoes) & Commercial (MediHandTrace) & Patient area entry/exit events \\
\hline RFID reader & $\begin{array}{l}\text { Floor (embedded under the dispenser, patient } \\
\text { room, and area entrance) }\end{array}$ & Commercial (MediHandTrace) & Patient area entry/exit events \\
\hline Dispenser & Patient room and hallway & Commercial (MediHandTrace) & Patient area entry/exit events \\
\hline \multicolumn{4}{|l|}{ Jain et al [83] } \\
\hline RFID tag & HCWs (tag) & Research & Patient room entry/exit events \\
\hline RFID reader & Dispenser and patient room entrance & Research & Patient room entry/exit events \\
\hline Dispenser & Patient room and hallway & Research & Patient room entry/exit events \\
\hline \multicolumn{4}{|l|}{ Johnson et al [84] } \\
\hline RFID tag & HCWs (tag) & Research & Patient room entry/exit events \\
\hline RFID reader & Patient room entrance & Research & Patient room entry/exit events \\
\hline Dispenser & Patient room entrance & Research & Patient room entry/exit events \\
\hline \multicolumn{4}{|l|}{ Radhakrishna et al [99] } \\
\hline RFID tag & HCWs (tag) & Research & Patient area entry/exit events \\
\hline RFID reader & Patient trolley (around patient bed) & Research & Patient area entry/exit events \\
\hline Dispenser & Patient trolley (around patient bed) & Research & Patient area entry/exit events \\
\hline Motion sensor & Patient trolley (around patient bed) & Research & Patient area entry/exit events \\
\hline \multicolumn{4}{|l|}{ Levin et al [90] } \\
\hline RFID tag & HCWs (bracelet) & Research & Patient area entry/exit events \\
\hline RFID reader & Patient bed, Dispenser & Research & Patient area entry/exit events \\
\hline Dispenser & $\mathrm{N} / \mathrm{A}^{\mathrm{b}}$ & Research & Patient area entry/exit events \\
\hline $\mathrm{IMU}^{\mathrm{c}}$ & HCWs (bracelet) & Research & Patient area entry/exit events \\
\hline \multicolumn{4}{|l|}{ Pleteršek et al [97] } \\
\hline RFID tag & HCWs (tag) & Research & Hand hygiene events \\
\hline Ethanol sensor & HCWs (tag), Patient room entrance & Research & Hand hygiene events \\
\hline \multicolumn{4}{|l|}{ Infrared } \\
\hline Baslyman et al [72] & & & \\
\hline
\end{tabular}




\begin{tabular}{|c|c|c|c|}
\hline Paper and system description & Device location & System type & $\begin{array}{l}\text { System metrics (hand hygiene } \\
\text { opportunities) }\end{array}$ \\
\hline Infrared transmitter & $\begin{array}{l}\text { Patient bed, patient room entrance, dispenser, } \\
\text { and hallway }\end{array}$ & Commercial (Ekahau) & Patient area entry/exit events \\
\hline Infrared receiver & HCWs (tag) & Commercial (Ekahau) & Patient area entry/exit events \\
\hline Dispenser & Patient room & Commercial (Ekahau) & Patient area entry/exit events \\
\hline \multicolumn{4}{|l|}{ Boyce et al [74] } \\
\hline Infrared transmitter & Patient bed, dispenser, hallway, and nurse station & Research & Patient area entry/exit events \\
\hline Infrared receiver & HCWs (tag) & Research & Patient area entry/exit events \\
\hline Dispenser & N/A & Research & Patient area entry/exit events \\
\hline \multicolumn{4}{|c|}{ Levchenko et al [86-89] and Pong et al [98] } \\
\hline Infrared transmitter & $\begin{array}{l}\text { Individual patient environments, room entrances, } \\
\text { shared bathrooms, dirty utility rooms (ceiling), } \\
\text { and dispenser }\end{array}$ & Research & Patient room entry/exit events \\
\hline Infrared receiver & HCWs (tag) & Research & Patient room entry/exit events \\
\hline Wall-mount dispenser & N/A & Research & Patient room entry/exit events \\
\hline Wearable gel dispenser & HCWs & Research & Patient room entry/exit events \\
\hline \multicolumn{4}{|l|}{ Dyson et al [77] } \\
\hline Infrared transmitter & Patient room and area entrance and sink (ceiling) & N/A & Patient area entry/exit events \\
\hline Infrared receiver & HCWs (tag) & N/A & Patient area entry/exit events \\
\hline Ethanol sensor & HCWs (tag) & N/A & Patient area entry/exit events \\
\hline
\end{tabular}

Ultrasound

Fisher et al [79]

Ultrasound transmitter

Ultrasound receiver

Dispenser

Srigley et al [100]

Ultrasound transmitter

Ultrasound receiver

Dispenser

Bluetooth low energy (BLE)

\section{Karimpour et al [85]}

BLE transmitter
BLE receiver

Room

HCWs (smartphone)

Misra et al [94]

BLE transmitter

BLE receiver

Dispenser

\section{Marques et al [91]}

BLE transmitter

BLE receiver

Dispenser

\section{IEEE 802.15.4/ZigBee}

Patient bed and dispenser

HCWs (tag)

Patient room

HCWs (tag)

Patient room, hallway, and dispenser

N/A

N/A

N/A

N/A

N/A

N/A

N/A

Research

Research

Patient bed and dispenser

Research

HCWs (smartphone)

Patient bed

Research

Research

Patient room and area entrance, sink, and dis- Research penser

HCWs (smartphone)

Patient room and area entrance
Research

Research
Patient area entry/exit events

Patient area entry/exit events

Patient area entry/exit events

Hand hygiene events

Hand hygiene events

Hand hygiene events

Patient area entry/exit events

Patient area entry/exit events

Patient area entry/exit events

Patient area entry/exit events

Patient area entry/exit events

Patient area entry/exit events

Patient area entry/exit events

Patient area entry/exit events 


\begin{tabular}{|c|c|c|c|}
\hline Paper and system description & Device location & System type & $\begin{array}{l}\text { System metrics (hand hygiene } \\
\text { opportunities) }\end{array}$ \\
\hline ZigBee transmitter & HCWs (tag) & $\begin{array}{l}\text { Commercial (Infectrack Sys- } \\
\text { tem) }\end{array}$ & Patient area entry/exit events \\
\hline ZigBee receiver & Patient bed and dispenser & $\begin{array}{l}\text { Commercial (Infectrack Sys- } \\
\text { tem) }\end{array}$ & Patient area entry/exit events \\
\hline Dispenser & Patient room & $\begin{array}{l}\text { Commercial (Infectrack Sys- } \\
\text { tem) }\end{array}$ & Patient area entry/exit events \\
\hline
\end{tabular}

Fries et al [80], Herman et al [81], Hornbeck et al [82], Polgreen et al [92], and Monsalve et al [95,96]

$\begin{array}{llll}\begin{array}{l}\text { IEEE 802.15.4 transmit- } \\ \text { ter }\end{array} & \text { Patient bed and dispenser } & \text { Research } & \text { Patient area entry/exit events } \\ \text { IEEE 802.15.4 receiver } & \text { HCWs (tag) } & \text { Research } & \text { Patient area entry/exit events } \\ \text { Dispenser } & \text { Patient room } & \text { Research } & \text { Patient area entry/exit events }\end{array}$

Wi-Fi

Wan et al [101]

$\begin{array}{llll}\text { Wi-Fi transmitter } & \text { Room and sink } & \text { Research } & \text { Hand hygiene events } \\ \text { Wi-Fi receiver } & \text { HCWs (tag) } & \text { Research } & \text { Hand hygiene events } \\ \text { Sink } & \text { Room } & \text { Research } & \text { Hand hygiene events }\end{array}$

${ }^{\mathrm{a}} \mathrm{HCW}$ : health care worker.

${ }^{\mathrm{b}} \mathrm{N} / \mathrm{A}$ : not applicable.

Of the 32 studies, $3(9 \%)$ studies developed RTLSs based on BLE technology $[85,91,94]$. BLE or Bluetooth is a wireless technology standard used for exchanging data between devices through ultra-high-frequency radio waves. These BLE-based RTLSs also contained transmitters (or beacons), BLE receivers, and dispensers. These transmitters were used as location reference points by placing BLE transmitters in health care settings. BLE receivers brought by HCWs could detect HCWs' real-time location to infer patient room entry/exit events. Unlike the aforementioned RTLSs, BLE receivers could be HCWs' own smartphones instead of carrying additional equipment. To measure hand hygiene events, dispensers triggered the embedded BLE transmitters once they were actuated.

Of the 32 studies, 8 (25\%) studies used IEEE 802.15.4 or ZigBee-based RTLSs [67,78,80-82,92,95,96]. IEEE 802.15.4 is a wireless standard capable of low-power, low-cost wireless communication between devices with lower power consumption. ZigBee is a wireless mesh network specification based on the IEEE 802.15.4 standard [118]. Similar to other RTLSs, they comprise transmitters, receivers, and dispensers. Transmitters were either carried by HCWs or placed in a health care environment. Two individual systems were used in the studies, including one commercial system (Infectrack System, i-HealthSys) based on ZigBee and one in-house system based on IEEE 802.15.4. After collecting the relative distance and/or HCWs' identity from transmitters, receivers could identify HCWs' movement when HCWs entered or exited patient areas. The transmitters or receivers were also embedded inside dispensers to recognize hand hygiene events.

The last technology used in RTLSs was Wi-Fi [101]. Wi-Fi is a family of wireless network protocols for building wireless network connections between devices through radio waves. Wi-Fi transmitters were deployed across a room and above a sink, and when HCWs triggered the dispenser next to the sink, the dispenser transmitted the dispensing event to a server through the sink transmitter. The receivers were carried by HCWs, scanned for transmitters in the environment, and periodically uploaded their location to a server.

\section{Quality Monitoring Systems}

Of the 89 studies, 21 (24\%) studies evaluated hand hygiene quality as performed by HCWs, grouped into 2 categories based on their measurement methods: (1) compliance with the WHO 6 -step hand hygiene techniques $(14 / 21,67 \%)$ and (2) surface coverage or illumination reduction of fluorescent substances $(7 / 21,33 \%)$.

\section{Compliance With WHO 6-Step Hand Hygiene Techniques}

Of the 21 studies, $14(67 \%)$ studies used a variety of sensors to monitor hand hygiene quality based on compliance with the WHO 6-step hand hygiene techniques (Figure 2). A common practice was to detect the duration of hand hygiene, which is considered a key indicator of quality [13,119]. Furthermore, these systems could recognize HCWs' hand motions as belonging to the individual steps from the WHO 6-step hand hygiene techniques. As such, these systems provided more details regarding HCWs' hand hygiene performance, including missed steps and out-of-order sequences, as noncompliance with all steps of hand hygiene procedures fails to cover all skin surfaces $[14,20]$. In these studies, sensors were either placed in the environment or attached to HCWs to monitor their hand hygiene performance (details are included in Table 5). 
Table 5. Description of studies monitoring compliance with the WHOa 6-step hand hygiene techniques.

\begin{tabular}{|c|c|c|c|}
\hline Paper and system description & Device location & System type & $\begin{array}{l}\text { System metrics (compliance with hand hygiene tech- } \\
\text { niques) }\end{array}$ \\
\hline
\end{tabular}

\section{Environmental sensor}

\section{Khan et al [106]}

$\mathrm{RGB}^{\mathrm{b}}$ camera

Motion sensor

Lacey et al [103]

RGB camera

Camilus et al [102]

Depth camera

Sink

Research

Zhong et al [104]

Depth camera

Khamis et al [105]

mmWave radar

Wearable sensor

Galluzzi et al [52,68]

$\mathrm{IMU}^{\mathrm{c}}$

$\mathrm{HCWs}^{\mathrm{d}}$ (wristwatch) Research

Li et al [69]

IMU

\section{Wijayasingha et al [70]}

IMU

Microphone

Banerjee et al [107]

IMU

Kutafina et al [108,109]

IMU

$\mathrm{sEMG}^{\mathrm{e}}$

Wang et al [110]

IMU

sEMG

\section{Zhong et al [41]}

RGB camera

HCWs (wristwatch) Research

HCWs (armband) Research

$\begin{array}{ll}\text { Sink } & \text { Research } \\ \text { Sink } & \text { Research } \\ \text { Sink } & \begin{array}{l}\text { Commercial (Sure- } \\ \text { Wash) }\end{array}\end{array}$

Hand hygiene duration

Hand hygiene duration

An unknown number of individual steps (WHO 6-step hand hygiene technique)

6 individual steps (WHO 6-step hand hygiene technique) and 1 wild hand hygiene technique

9 individual steps (WHO 6-step hand hygiene technique)

9 individual steps (WHO 6-step hand hygiene technique)

12 individual steps (WHO 6-step hand hygiene technique), 1 wild hand hygiene technique

13 individual steps (WHO 6-step hand hygiene technique)

9 individual steps (WHO 6-step hand hygiene technique)

9 individual steps (WHO 6-step hand hygiene technique)

6 individual steps (self-defined hand hygiene technique)

9 individual steps (WHO 6-step hand hygiene technique)

9 individual steps (WHO 6-step hand hygiene technique)

14 individual steps (WHO 6-step hand hygiene technique)

14 individual steps (WHO 6-step hand hygiene technique)

${ }^{\mathrm{a}}$ WHO: World Health Organization.

${ }^{\mathrm{b}} \mathrm{RGB}$ : red green blue.

${ }^{\mathrm{c}}$ IMU: inertial measurement unit.

${ }^{\mathrm{d}} \mathrm{HCW}$ : health care worker.

esEMG: surface electromyography.

Of the 14 studies, 5 (36\%) studies measured compliance with the WHO 6-step hand hygiene techniques by placing sensors in the environment [102-106]. Khan et al [106] placed an RGB camera and a motion sensor above the sink in operation rooms to monitor HCWs' hand hygiene duration. Lacey et al [103] used a commercial automatic video auditing system (SureWash, 
GLANTA Ltd) to monitor HCWs' compliance with the WHO 6-step techniques. Camilus et al [102] and Zhong et al [104] installed an RGB-depth camera (Kinect) above a sink to record hand hygiene events. Hand hygiene videos with stereo information were then analyzed by classifying each frame as an individual step from the 6-step hand hygiene techniques. Instead of using optical sensors, Khanmis et al [105] installed an mmWave sensor above a sink to measure hand hygiene performance. The mmWave is a sensing technology for detecting objects and provides the range, velocity, and angle of these objects. By using the generated frames from mmWave signals, they could classify each frame as one of the nine individual steps in line with the 6-step hand hygiene techniques.

Of the 14 studies, 9 (64\%) studies monitored compliance with hand hygiene guidelines by attaching wearable sensors to HCWs [41,52,68-70,107-110]. Of these, the IMU was the most popular sensor and was used in $89 \%(8 / 9)$ of studies with several supplementary sensors. As mentioned above, the IMU can measure a body's specific force, angular rate, and orientation. Approximately $44 \%$ (4/9) of studies used the IMU of wristwatches to collect physical signals during hand hygiene events and classified hand motion within a certain time frame as one of the several individual steps of the 6-step hand hygiene techniques [52,68-70]. In addition, microphones have been combined with IMUs to evaluate hand hygiene performance, as the additional audio data could further improve the system accuracy [70]. Owing to hygiene reasons, 44\% (4/9) of studies used sensor armbands (Myo armband, North Inc) with IMU to detect HCWs' compliance with hand hygiene techniques [107-110]. Of these 4 studies, 3 (75\%) studies used both IMU and surface electromyography (sEMG) sensors from Myo armbands to recognize individual steps in line with 6-step hand hygiene techniques [108-110]. The sEMG sensor is an electrochemical sensor that detects biopotentials using electrodes placed on the skin. In contrast to the aforementioned studies, Zhong et al [41] attached an RGB camera to HCWs' chests. The camera recorded HCWs' hand hygiene practices, and then the collected RGB videos were processed by a deep learning algorithm (two-stream convolutional neural network) to classify hand motions into 7 self-defined hand hygiene steps.

\section{Surface Coverage or Illumination Reduction of Fluorescent Substances}

Of the 21 studies, 7 (33\%) studies used fluorescent substances to automatically examine hand hygiene quality by computer vision algorithms. However, the means of detecting the quality of handwash and hand rub were distinct. For handwash, participants first applied fluorescent dye on their entire hands and then washed their hands with soap and tap water thoroughly. For hand rub, a hand disinfectant was mixed with a fluorescent dye, and participants used the disinfectant to perform an episode of hand rub. Then, their hands were checked under a UV light lamp and photographed using RGB cameras for further analysis. By comparing the disinfected areas that glowed under UV light and were free from pathogens, Lehotsky et al [120] stated that fluorescent substances could highlight the areas of the hand surface that were adequately disinfected with acceptable accuracy (95\% sensitivity and $98 \%$ specificity). UV tests have been widely used to assess hand hygiene quality in medical education because of their easy application, low associated costs, and well-visible results [22].

There were two main ways to automatically analyze the collected RGB images: detecting illumination reduction before and after an episode of handwash or measuring the surface coverage of fluorescent substances (details included in Table 6). Approximately $29 \%(2 / 7)$ of studies calculated the illumination difference of fluorescent substances before and after an episode of handwash using Adobe Photoshop (Adobe Inc) and MATLAB (The Math Works, Inc) [25,111]. Hand hygiene quality was then measured by the value of illumination difference, where a bigger difference indicates better hand hygiene performance and vice versa.

Of the 7 studies, 5 (71\%) studies analyzed the collected images from both handwash and hand rub by measuring the surface coverage of fluorescent substances [112-116]. For hand rub, the hand rub quality was acceptable if all areas were bright without dark spots, therefore suggesting that all parts of the hand were covered homogeneously with disinfectant [22]. Approximately $40 \%(2 / 5)$ of studies focused on measuring the surface coverage of fluorescent substances after hand rub by applying clustering algorithms [112,113]. For handwash, as fluorescent substances contaminated hands in advance, the handwash quality was measured by the range of cleaned hand areas (dark areas). Approximately 60\% (3/5) of studies applied specific threshold values or deep learning algorithms to measure handwash quality [114-116]. 
Table 6. Description of studies monitoring surface coverage or illumination reduction of fluorescent substances.

\begin{tabular}{|c|c|c|c|}
\hline Paper and system description & Device location & System type & System metrics (illumination reduction or surface coverage) \\
\hline \multicolumn{4}{|l|}{ Illumination reduction } \\
\hline \multicolumn{4}{|l|}{ Deochand et al [25] } \\
\hline Fluorescent substance & $\mathrm{HCWs}^{\mathrm{a}}$ (hand) & Research & Illumination reduction (whole hand) \\
\hline UV lamp & Opaque box & Research & Illumination reduction (whole hand) \\
\hline $\mathrm{RGB}^{\mathrm{b}}$ camera & Opaque box & Research & Illumination reduction (whole hand) \\
\hline \multicolumn{4}{|l|}{ Pellegrino et al [111] } \\
\hline Fluorescent substance & HCWs (hand) & Research & Illumination reduction (whole hand) \\
\hline UV lamp & Dark room & Research & Illumination reduction (whole hand) \\
\hline RGB camera & Dark room & Research & Illumination reduction (whole hand) \\
\hline \multicolumn{4}{|l|}{ Surface coverage } \\
\hline \multicolumn{4}{|l|}{ Srisomboon et al [112] } \\
\hline Fluorescent substance & HCWs (hand) & Research & Surface coverage (pixel) \\
\hline UV lamp & Opaque box & Research & Surface coverage (pixel) \\
\hline RGB camera & Opaque box & Research & Surface coverage (pixel) \\
\hline \multicolumn{4}{|l|}{ Szilágyi et al [113] } \\
\hline Fluorescent substance & HCWs (hand) & Research & Surface coverage (pixel) \\
\hline UV lamp & Opaque box & Research & Surface coverage (pixel) \\
\hline RGB camera & Opaque box & Research & Surface coverage (pixel) \\
\hline \multicolumn{4}{|l|}{ Yamamoto et al $[114,115]$} \\
\hline Fluorescent substance & HCWs (hand) & Research & Surface coverage (segment) \\
\hline UV lamp & Opaque box & Research & Surface coverage (segment) \\
\hline RGB camera & Opaque box & Research & Surface coverage (segment) \\
\hline \multicolumn{4}{|l|}{ Naim et al [116] } \\
\hline Fluorescent substance & HCWs (hand) & Research & Surface coverage (pixel) \\
\hline UV lamp & Opaque box & Research & Surface coverage (pixel) \\
\hline RGB camera & Opaque box & Research & Surface coverage (pixel) \\
\hline
\end{tabular}

${ }^{\mathrm{a}} \mathrm{HCW}$ : health care worker.

${ }^{\mathrm{b}} \mathrm{RGB}$ : red green blue.

\section{Discussion}

Recently, there has been increased interest in developing electronic monitoring systems to serve as an alternative or supplementary hand hygiene monitoring approach [19]. However, electronic hand hygiene monitoring systems do have limitations. The following sections discuss the limitations related to accuracy, data integration, privacy and confidentiality, potential risks, usability, associated costs, and infrastructure improvements $[19,121]$.

\section{System Accuracy}

The system accuracy of electronic hand hygiene monitoring systems is the top concern for HCWs $[121,122]$. However, systems come with different metrics without standardized measurement tools. System accuracy is also affected by technical issues and geometric constraints.
The metrics often vary substantially in different types of electronic hand hygiene monitoring systems. For electronic hand hygiene compliance monitoring systems, the metrics are based on the number of detectable moments for hand hygiene described by the WHO (Figure 1). A total of 4 different metrics were mentioned in the included studies: (1) hand hygiene events, (2) patient room entry/exit events, (3) patient area entry/exit events, and (4) the WHO 5 moments for hand hygiene. Similarly, the metrics for electronic hand hygiene quality monitoring systems are also disparate. One way to measure HCWs' hand hygiene quality is through detecting their compliance with the WHO 6-step hand hygiene techniques (Figure 2). However, different systems often recognize different sets of individual steps of standardized techniques, which can vary between 6 and 14 individual steps. Detecting illumination reduction or surface coverage of fluorescent substances is another way to measure hand hygiene quality; however, different studies come with different metrics. Several systems can detect 
pixel or segment levels of fluorescent areas from the collected RGB images; however, others measure the illumination reduction of the entire hand. Therefore, system results may not accurately reflect HCWs' hand hygiene compliance and quality, and results cannot be compared between different studies without further processing.

Technical issues dramatically affect system accuracy. One of the major concerns is hardware limitations, which result in systems not functioning well under certain situations. For instance, infrared-based RTLS could fail to work if an infrared transmitter or receiver taken by a person is obscured by objects or cloths as the infrared wave cannot penetrate opaque materials [123]. Systems using ethanol sensors to track alcohol-based hand rubs cannot sense HCWs' handwash events [77]. Systems solely relying on motion sensors (ie, without user identity) cannot provide information on who enters or exits patient rooms. Other systems also suffer from reflected signals, signal noise, and interference. Moreover, the algorithms used in these systems may introduce a variety of errors. An example is that machine learning algorithms used to recognize HCWs' compliance with WHO 6-step hand hygiene techniques can generate incorrect classifications [110]. In some extreme cases, these algorithms may not correctly recognize any individual steps and provide an entire sequence of erroneous predictions. Thus, both hardware and algorithm limitations need to be considered when implementing hand hygiene monitoring systems, and effective validation of an electronic hand hygiene monitoring system is required to identify associated technical issues.

System accuracy is also influenced by geometric constraints. To protect patient privacy, studies may attach a curtain in front of cameras [36] or point them toward nonsensitive regions only (handwashing sinks and sanitizer dispensers) [38], which may not allow observation of all hand hygiene opportunities and events and further affect system accuracy. Furthermore, systems based on wearable devices are restricted by device position. For example, recent studies have relied on sensor armbands to detect hand hygiene quality; however, their system accuracy is greatly affected by the actual armband position on the arm [110].

\section{Data Integration}

The use of multiple types of sensor data and system records raises new challenges for data integration. Systems use multiple sensors to collect more reliable, accurate, and useful information required for hand hygiene monitoring; however, sensor data fusion comes with problems and issues. One of the most common issues is sensor registration and calibration, as individual sensors have their own local reference frames [124]. Studies applied varying technologies to convert different data from multiple sensors (eg, IMU and sEMG) into one reference frame and starting time, including network time protocols, event-based synchronization methods, and their combination $[125,126]$. During data fusion and calibration, diverse formats of sensor data could also generate noise and ambiguity, resulting in competitive and conflicting errors, and adding redundancy of sensor data is one of the solutions to increase system reliability [124]. Other issues with multiple sensor data include granularity, timescale, and frequency [124].
Integrating hand hygiene data observed by different systems is another challenge. To increase result accuracy and credibility, studies might use multiple complementary systems to monitor hand hygiene compliance or quality among the same group of HCWs. However, the metric for each observation method was different, and a lack of correlation with their results raised concerns regarding data validity [32]. In addition, different data and result formats raise issues of data integration and require conversion. Moreover, systems could simultaneously observe hand hygiene compliance and quality; however, the means to store and retrieve the records of compliance rate and quality are unclear [41,52,68-70].

\section{Privacy and Confidentiality}

Privacy and confidentiality are two other major concerns associated with electronic hand hygiene monitoring systems. Privacy concerns are known to influence HCWs' attitudes toward electronic hand hygiene monitoring systems [19]. Some HCWs perceive these systems as an invasion of their privacy and a pretext for constant surveillance of their daily activities, which makes HCWs distrust these systems and refuse to change their hand hygiene behaviors [121]. Electronic hand hygiene monitoring systems also create special challenges regarding patient privacy [127]. Studies using video cameras to monitor all 5 moments of hand hygiene would require constant video surveillance of patients and patient rooms, resulting in violation of patient privacy [26]. However, limited studies have mentioned patient privacy protection before implementing electronic hand hygiene systems. Moreover, constant surveillance through electronic hand hygiene monitoring systems might raise legal issues, resulting in systems that are unpractical in health care settings, especially when involving cameras and microphones.

The continuous collection of personal data in unprecedented volumes also raises data security concerns [128]. During data collection and storage, users' personal information can be exposed to unauthorized third parties, and the collected data can also be modified or altered through communication protocols (eg, Wi-Fi and Bluetooth) [128]. Furthermore, use scenarios of the collected data are another noticeable concern in hand hygiene monitoring systems for HCWs. Ellingson et al [122] noted that HCWs were worried about the potential use of adherence data for punitive purposes. Thus, an efficient communication mechanism should be established to provide information to HCWs on what data will be collected and stored and how data will be used [121].

\section{Potential Risks}

HCWs may face some potential risks caused by electronic hand hygiene monitoring systems. One potential risk is UV-related skin and eye damage caused by UV lamps, which are used to detect HCWs' hand hygiene quality [129,130]. Efficient preventive measures should be placed to protect HCWs' safety and control their daily exposure under a threshold limit of 3.0 $\mathrm{mJ} / \mathrm{cm}^{2}$ [129]. Wearable sensors have gained popularity to assess HCWs' hand hygiene quality, especially wristwatches. However, wearing rings, wristwatches, and bracelets could cause hand contamination [131]; therefore, it is challenging to use wristwatches to monitor hand hygiene procedure compliance, as it can possibly defeat the purpose. Moreover, Ward et al [26] 
noted that during the demolition and installation of monitoring systems in health care, the released particulates such as mold or fungus might increase the risk of infection.

Another risk of deploying electronic hand hygiene systems is radio-frequency interference (RFI) with medical devices. RFI, known as a subset of electromagnetic interference, has been reported to cause medical device failure because of interference from various emitters of radio-frequency energy [132]. Badizadegan et al [133] reported that RFI could also result in erroneous laboratory results. Specifically, van der Togt et al [134] noted that RFID might induce potentially hazardous incidents in medical devices. To prevent RFI-associated medical device failures, system designers and device manufacturers should ensure conformance with current RFI standards, and on-site electromagnetic interference tests are required during implementation [132].

\section{Usability}

Another challenge for implementing electronic hand hygiene monitoring systems in health care is usability, as the technology may interrupt HCWs' daily workflow to ensure the proper functioning of systems. These usability problems consist of hardware and information delivery. Conway et al [121] summarized hardware-associated usability problems of compliance monitoring systems, including wearable tags (1) as heavy, bulky, and difficult to use; (2) requiring battery power, but batteries are not durable with frequent battery failures; and (3) requiring HCWs to wear them in certain positions. Other usability problems, such as limited sensing range and angles, require $\mathrm{HCW}$ to change their behavior to ensure that systems work properly [77].

Similarly, usability issues also exist when delivering HCWs' hand hygiene performance information. For hand hygiene compliance monitoring, systems use different types of instant prompts (eg, visual reminders, auditory reminders, vibrations, face-to-face feedback, and olfactory stimulus) to remind HCWs regarding missed hand hygiene opportunities; however, these prompts are associated with several usability problems. For example, Dyson et al [77] noted that systems using visual prompts with a red light could cause patient anxiety. Regarding instant prompts for inadequate hand hygiene quality, most systems are designed for medical training purposes, and thus, efficient delivery of instant feedback to HCWs about hand hygiene quality and integrating these systems into their daily routines are still open challenges.

\section{Associated Costs and Infrastructure Improvements}

Implementing an electronic hand hygiene monitoring system in health care facilities comes with high costs and infrastructure improvements [19,26,121]. Using electronic systems first requires expenditure on equipment and installation costs, which vary with the selected systems [19,26,121]. Morgan et al [59] estimated that the installation of electronic dispenser-assisted systems in a 15-bed intensive care unit requires a cost between US \$30,000 and US \$40,000. Another study installed 21 video cameras in the hallways and patient rooms of a 17-bed intensive care unit, costing US $\$ 50,000$ [38]. For community settings, installing a complete set of electronic hand hygiene monitoring systems is not realistic. Instead of fixing sensors in the environment, studies attached wearable sensors to HCWs or embedded sensors into soap bars to track HCWs' hand hygiene events from their daily routines, which are more scalable and economical.

Except for expenditures on equipment and installation costs, maintenance and personnel costs represent a larger part of system-associated costs. Maintenance costs include system updates, hand rub and soap supplies, an increase in monitored HCWs, and replacement of batteries and defective devices [19]. For in-house systems, technology does not guarantee accurate measurements and requires continuous iteration developments, resulting in maintenance costs and increased personnel needs. Application-assisted direct observation and camera-assisted observation with human auditors are associated with high personnel costs, as these systems require in-house or remote auditors to continually observe hand hygiene opportunities and events.

The installation of electronic hand hygiene systems may disrupt physical infrastructure and require infrastructure improvements. Conway et al [121] noted that infrastructure improvements comprise existing dispenser replacement and fixed hard wiring. As wireless network infrastructure also dramatically affects the system performance, it should be arranged and updated when deploying such systems in health care facilities with outdated network infrastructure.

\section{Performance Feedback}

An important but sometimes overlooked aim of deploying electronic hand hygiene monitoring systems in health care settings is to provide educational interventions to HCWs and improve their practices. The intervention methods used in the included studies comprised instant prompts and periodic summaries.

To remind HCWs about missed hand hygiene opportunities, systems may provide instant prompts when noncompliance is detected. Instant prompts comprise visual reminders, auditory reminders, vibrations, face-to-face feedback, olfactory stimuli, and their combinations. To improve HCWs' hand hygiene quality, systems also provide instant prompts when detecting hand hygiene events with inadequate quality. Instant prompts include reminding HCWs about missed steps and disordered sequences of the WHO 6-step hand hygiene techniques and visualizing unclean areas from recorded UV test images. Periodic summaries are also widely adopted to improve HCWs' hand hygiene compliance and quality. Systems deliver periodic summaries to HCWs through reports, dashboards, games, notice boards/monitors, face-to-face feedback, and their combinations.

The included studies also delivered hand hygiene feedback by combining both instant prompts and periodic summaries. For example, Ellison et al [51] adopted auditory reminders as instant prompts and delivered periodic summaries through specific monitor screen savers to remind HCWs of hand hygiene compliance.

Nevertheless, each instant prompt type is associated with specific drawbacks. For visual reminders, Dyson et al [77] noted that red light light-emitting diodes (LEDs) on badges might 
cause patient anxiety, so the color of badge LEDs should be adjustable and provide an option to disable the LEDs when necessary. Regarding auditory reminders, Baslyman et al [72] noted that sending audible alerts during the night is not acceptable as most patients are sleeping. Face-to-face feedback is associated with the Hawthorne effect, which causes different hand hygiene behaviors from their daily routines [30]. Using unpleasant odors is also not suitable for most health care facilities as they may cause physical discomfort.

Regarding periodic summaries, designing understandable periodic summaries for $\mathrm{HCWs}$ with different educational backgrounds is a challenge [121]. Conway et al [48] noted that HCWs or managers might have difficulty reading and interpreting periodic reports with charts. Efficiently disseminating collected information to HCWs and keeping them informed is challenging as well, as many HCWs have reported never or inconsistently receiving their performance information [48]. Moreover, ensuring that periodic summaries are used to drive hand hygiene improvement instead of punishment is another challenge. Hand hygiene improvement might be short-lived and moderate without HCWs' engagement, constant feedback delivery, detailed action plans, and leadership support [121].

By constantly delivering feedback to HCWs and educating HCWs and medical students on the importance of hand hygiene and the correct procedures, HCWs are likely to improve their hand hygiene techniques and habits. In Multimedia Appendices $3[53,66,67,77,79,89,98,111], 4[35,38,39,44,48,51,79,106]$, and $5[30,51,88,89]$, we summarize the performance improvements of HCWs in studies that implemented instant prompts, periodic summaries, or their combinations. However, HCWs have diverse feedback needs. For example, Conway et al [121] and Levchenko et al [89] noted that most HCWs prefer instant prompts rather than periodic summaries, and their compliance rates increased immediately after receiving instant prompts. Nevertheless, Levchenko et al [89] also mentioned that a few HCWs improved their compliance only after they reviewed their individual results.

\section{Implications}

Owing to the high level of heterogeneity of the included studies, it is difficult to compare and analyze data across studies. A noticeable difference across the included studies was the variety of system metrics. To generate quantitative analyses, a high degree of standardization is required. Thus, standardized metrics across different hand hygiene monitoring systems need to be established based on system hardware limitations and WHO recommendations. For instance, the number of individual steps of the WHO 6-step hand hygiene techniques can be set to 9 in line with the WHO guideline as steps 3, 6, and 7 (shown in Figure 2) require repeats for both hands.

Given the recent advancements in sensing technologies, hand hygiene monitoring systems can adopt previously unused technology infrastructure or sensors to monitor HCWs' hand hygiene performance. For example, the aforementioned systems require a dedicated device being carried by HCWs to trace their indoor locations. Li et al [135] achieved device-free indoor location tracking by using commodity Wi-Fi, which has been installed in most health care facilities. Conversely, hand hygiene monitoring systems can apply new algorithms to improve their system accuracy. For example, previous studies adopted a hidden Markov model to classify the individual steps of 6-step techniques or smooth classification results, which assumes that HCWs will perform hand hygiene procedures according to predefined orders. However, once this assumption is relaxed, the performance of these systems dramatically drops [69]. Instead, classification results smoothed by change point detection algorithms (eg, E.Divisive [136]) might ease the performance decrease.

Hand hygiene monitoring systems and collected data can also be used to solve other hand hygiene-related issues. For example, systems detecting surface coverage of fluorescent substances could be considered as an alternative method to validate the efficacy of newly proposed hand hygiene techniques instead of microbiological tests, as fluorescent substances could highlight the hand surface areas that are adequately disinfected with acceptable accuracy [120]. Similarly, studies have used hand hygiene behavior data to monitor participants' levels of dementia, Alzheimer disease, and obsessive-compulsive disorder $[137,138]$. Furthermore, hand hygiene compliance history has been used to simulate the transmission of HAIs in health care settings [139].

\section{Limitations}

This study has several limitations. Some relevant studies may have been missed because of the keywords and databases chosen for the search query. Furthermore, some relevant studies may not have been included if they were not published in English, were outside the specified time frame, or did not provide adequate technical information.

Specifically, we included all types of studies regardless of their maturity, as it helps summarize the latest technological developments in electronic hand hygiene monitoring systems. However, early-stage or preliminary studies or methodology studies may present incomplete data or a lack of results. Owing to the heterogeneity of the studies and sparse metrics, we could not conduct a meta-analysis for the study population, system accuracy, and intervention effectiveness. In addition, because of the significant heterogeneity, we could not evaluate the risk of bias for each study using standardized automation tools and assess the certainty of the included studies.

This review describes different technologies for hand hygiene monitoring. Nevertheless, since we adopted the narrative approach to synthesize the outcomes rather than a meta-analysis, we did not assess the risk of bias because of missing results.

\section{Conclusions}

Our review provides an overview of the latest technological developments in electronic hand hygiene monitoring systems that measure compliance or quality. Systems utilize application-assisted direct observation, camera-assisted observation, sensor-assisted observation, and RTLS to monitor HCWs' compliance rates. For quality monitoring, systems either measure compliance with the WHO 6-step hand hygiene techniques or detect surface coverage or illumination reduction of fluorescent substances. Despite the technologies used in these 
systems, we identify system-associated issues and challenges, including system accuracy, data integration, privacy and confidentiality, potential risks, usability, and associated costs and infrastructure improvements. Owing to the narrative approach adopted in these studies, more research is required to establish standardized metrics to measure system performance differences among electronic hand hygiene monitoring systems. With sensing technologies and algorithms continually advancing, more research is needed on their implementation to improve system performance and address other hand hygiene-related issues.

\section{Acknowledgments}

This work was partially funded by the Australian Research Council Discovery Project DP190102627 and the National Health and Medical Research Council grants 1170937 and 2004316. CW was supported by a PhD scholarship provided by the Australian Commonwealth Government Research Training Program.

\section{Conflicts of Interest}

None declared.

\section{Multimedia Appendix 1}

Search strategy for PubMed, IEEE Xplore Digital Library, and ACM Digital Library.

[XLSX File (Microsoft Excel File), $10 \mathrm{~KB}$-Multimedia Appendix 1]

\section{Multimedia Appendix 2}

Data extraction form.

[XLSX File (Microsoft Excel File), 11 KB-Multimedia Appendix 2]

\section{Multimedia Appendix 3}

Hand hygiene improvements of studies with instant prompts.

[XLSX File (Microsoft Excel File), 10 KB-Multimedia Appendix 3]

\section{Multimedia Appendix 4}

Hand hygiene improvements of studies with periodic summaries.

[XLSX File (Microsoft Excel File), 10 KB-Multimedia Appendix 4]

\section{Multimedia Appendix 5}

Hand hygiene improvements of studies with instant prompts and periodic summaries.

[XLSX File (Microsoft Excel File), 10 KB-Multimedia Appendix 5]

\section{References}

1. Allegranzi B, Pittet D. Role of hand hygiene in healthcare-associated infection prevention. J Hosp Infect 2009 Dec;73(4):305-315. [doi: 10.1016/j.jhin.2009.04.019] [Medline: 19720430]

2. World Health Organization. WHO guidelines on hand hygiene in health care. Geneva: World Health Organization; 2009:1-270.

3. Pittet D. Improving adherence to hand hygiene practice: a multidisciplinary approach. Emerg Infect Dis 2001 Apr;7(2):234-240 [FREE Full text] [doi: 10.3201/eid0702.010217] [Medline: 11294714]

4. Haque M, Sartelli M, McKimm J, Bakar M. Health care-associated infections - an overview. Infect Drug Resist 2018;11:2321-2333 [FREE Full text] [doi: 10.2147/IDR.S177247] [Medline: 30532565]

5. Institute of Medicine, Committee on Quality of Health Care in America. In: Donaldson MS, Corrigan JM, Kohn LT, editors. To Err Is Human: Building a Safer Health System. Washington (DC): National Academies Press (US); 2000.

6. Klevens RM, Edwards JR, Richards CL, Horan TC, Gaynes RP, Pollock DA, et al. Estimating health care-associated infections and deaths in U.S. hospitals, 2002. Public Health Rep 2007 Aug 02;122(2):160-166 [FREE Full text] [doi: 10.1177/003335490712200205] [Medline: 17357358]

7. De Angelis G, Murthy A, Beyersmann J, Harbarth S. Estimating the impact of healthcare-associated infections on length of stay and costs. Clin Microbiol Infect 2010 Dec;16(12):1729-1735 [FREE Full text] [doi:

10.1111/j.1469-0691.2010.03332.x] [Medline: 20673257]

8. Graves N, Halton K, Paterson D, Whitby M. Economic rationale for infection control in Australian hospitals. Healthc Infect 2009 Sep;14(3):81-88. [doi: 10.1071/hi09010] 
9. Stone PW, Hasan S, Quiros D, Larson EL. Effect of guideline implementation on costs of hand hygiene. Nurs Econ 2007;25(5):279-284 [FREE Full text] [Medline: 18080624]

10. How to handrub? / how to handwash? World Health Organization. 2009. URL: https://www.who.int/gpsc/5may/ How_To_HandWash_Poster.pdf [accessed 2021-10-21]

11. Pittet D, Simon A, Hugonnet S, Pessoa-Silva CL, Sauvan V, Perneger TV. Hand hygiene among physicians: performance, beliefs, and perceptions. Ann Intern Med 2004 Jul 06;141(1):1-8. [doi: 10.7326/0003-4819-141-1-200407060-00008] [Medline: 15238364]

12. Erasmus V, Daha TJ, Brug H, Richardus JH, Behrendt MD, Vos MC, et al. Systematic review of studies on compliance with hand hygiene guidelines in hospital care. Infect Control Hosp Epidemiol 2010 Mar 02;31(3):283-294. [doi: 10.1086/650451] [Medline: 20088678]

13. Korhonen A, Ojanperä H, Puhto T, Järvinen R, Kejonen P, Holopainen A. Adherence to hand hygiene guidelines - significance of measuring fidelity. J Clin Nurs 2015 Nov 01;24(21-22):3197-3205. [doi: 10.1111/jocn.12969] [Medline: 26331437]

14. Arias AV, Garcell HG, Ochoa YR, Arias KF, Miranda FR. Assessment of hand hygiene techniques using the World Health Organization's six steps. J Infect Public Health 2016 May;9(3):366-369 [FREE Full text] [doi: 10.1016/j.jiph.2015.11.006] [Medline: 26707705]

15. Szilágyi L, Haidegger T, Lehotsky A, Nagy M, Csonka E, Sun X, et al. A large-scale assessment of hand hygiene quality and the effectiveness of the "WHO 6-steps". BMC Infect Dis 2013 May 30;13(1):249 [FREE Full text] [doi:

10.1186/1471-2334-13-249] [Medline: 23718728]

16. Boyce JM. Measuring healthcare worker hand hygiene activity: current practices and emerging technologies. Infect Control Hosp Epidemiol 2011 Oct 02;32(10):1016-1028. [doi: 10.1086/662015] [Medline: 21931253]

17. Stewardson A, Sax H, Longet-Di Pietro S, Pittet D. Impact of observation and analysis methodology when reporting hand hygiene data. J Hosp Infect 2011 Apr;77(4):358-359. [doi: 10.1016/j.jhin.2010.12.008] [Medline: 21316121]

18. Boyce JM. Hand hygiene compliance monitoring: current perspectives from the USA. J Hosp Infect 2008 Oct;70:2-7. [doi: 10.1016/s0195-6701(08)60003-1]

19. Boyce JM. Electronic monitoring in combination with direct observation as a means to significantly improve hand hygiene compliance. Am J Infect Control 2017 May 01;45(5):528-535. [doi: 10.1016/j.ajic.2016.11.029] [Medline: 28456322]

20. Tschudin-Sutter S, Sepulcri D, Dangel M, Schuhmacher H, Widmer AF. Compliance with the World Health Organization hand hygiene technique: a prospective observational study. Infect Control Hosp Epidemiol 2015 Apr 20;36(4):482-483. [doi: 10.1017/ice.2014.82] [Medline: 25782907]

21. Reilly JS, Price L, Lang S, Robertson C, Cheater F, Skinner K, et al. A pragmatic randomized controlled trial of 6-step vs 3 -step hand hygiene technique in acute hospital care in the United Kingdom. Infect Control Hosp Epidemiol 2016 Jun 07;37(6):661-666. [doi: 10.1017/ice.2016.51] [Medline: 27050843]

22. Vanyolos E, Peto K, Viszlai A, Miko I, Furka I, Nemeth N, et al. Usage of ultraviolet test method for monitoring the efficacy of surgical hand rub technique among medical students. J Surg Educ 2015 May;72(3):530-535. [doi:

10.1016/j.jsurg.2014.12.002] [Medline: 25656633]

23. Kampf G, Ostermeyer C, Heeg P, Paulson D. Evaluation of two methods of determining the efficacies of two alcohol-based hand rubs for surgical hand antisepsis. Appl Environ Microbiol 2006 Jun;72(6):3856-3861. [doi: 10.1128/aem.02746-05]

24. Michaud RN, McGrath MB, Goss WA. Application of a gloved-hand model for multiparameter measurements of skin-degerming activity. J Clin Microbiol 1976 Apr;3(4):406-413 [FREE Full text] [doi: 10.1128/jcm.3.4.406-413.1976] [Medline: 1262452]

25. Deochand N, Deochand ME. Brief report on hand-hygiene monitoring systems: a pilot study of a computer-assisted image analysis technique. J Environ Health 2016 Jun;78(10):14-20. [Medline: 27348978]

26. Ward MA, Schweizer ML, Polgreen PM, Gupta K, Reisinger HS, Perencevich EN. Automated and electronically assisted hand hygiene monitoring systems: a systematic review. Am J Infect Control 2014 May;42(5):472-478. [doi: 10.1016/j.ajic.2014.01.002] [Medline: 24773785]

27. Marra AR, Edmond MB. Hand hygiene: state-of-the-art review with emphasis on new technologies and mechanisms of surveillance. Curr Infect Dis Rep 2012 Dec 28;14(6):585-591. [doi: 10.1007/s11908-012-0288-y] [Medline: 22922997]

28. Moher D, Shamseer L, Clarke M, Ghersi D, Liberati A, Petticrew M, PRISMA-P Group. Preferred reporting items for systematic review and meta-analysis protocols (PRISMA-P) 2015 statement. Syst Rev 2015 Jan 01;4(1):1 [FREE Full text] [doi: 10.1186/2046-4053-4-1] [Medline: 25554246]

29. Kariyawasam N, Wong M, Turner P. User centred design and nosocomials in surgical ICUs: a mobile application for peer monitoring and training in hand hygiene. Stud Health Technol Inform 2017;245:743-747. [Medline: 29295197]

30. Sickbert-Bennett EE, DiBiase LM, Willis TM, Wolak ES, Weber DJ, Rutala WA. Reducing health care-associated infections by implementing a novel all hands on deck approach for hand hygiene compliance. Am J Infect Control 2016 May 02;44(5 Suppl):13-16. [doi: 10.1016/j.ajic.2015.11.016] [Medline: 27131129]

31. Wiemken TL, Furmanek SP, Mattingly WA, Haas J, Ramirez JA, Carrico RM. Googling your hand hygiene data: using Google Forms, Google Sheets, and R to collect and automate analysis of hand hygiene compliance monitoring. Am J Infect Control 2018 Jun;46(6):617-619. [doi: 10.1016/j.ajic.2018.01.010] [Medline: 29496338] 
32. Magnus TP, Marra AR, Camargo TZ, Victor ED, da Costa LS, Cardoso VJ, et al. Measuring hand hygiene compliance rates in different special care settings: a comparative study of methodologies. Int J Infect Dis 2015 Apr;33:205-208 [FREE Full text] [doi: 10.1016/j.ijid.2015.02.016] [Medline: 25722282]

33. da Costa LS, Neves VM, Marra AR, Camargo TZ, dos Santos Cardoso MF, da Silva Victor E, et al. Measuring hand hygiene compliance in a hematology-oncology unit: a comparative study of methodologies. Am J Infect Control 2013 Nov;41(11):997-1000. [doi: 10.1016/j.ajic.2013.03.301] [Medline: 23769833]

34. Brotfain E, Livshiz-Riven I, Gushansky A, Erblat A, Koyfman L, Ziv T, et al. Monitoring the hand hygiene compliance of health care workers in a general intensive care unit: use of continuous closed circle television versus overt observation. Am J Infect Control 2017 Aug 01;45(8):849-854. [doi: 10.1016/j.ajic.2017.03.015] [Medline: 28479008]

35. Sánchez-Carrillo LA, Rodríguez-López JM, Galarza-Delgado D, Baena-Trejo L, Padilla-Orozco M, Mendoza-Flores L, et al. Enhancement of hand hygiene compliance among health care workers from a hemodialysis unit using video-monitoring feedback. Am J Infect Control 2016 Aug 01;44(8):868-872. [doi: 10.1016/j.ajic.2016.01.040] [Medline: 27068027]

36. Diller T, Kelly JW, Blackhurst D, Steed C, Boeker S, McElveen DC. Estimation of hand hygiene opportunities on an adult medical ward using 24-hour camera surveillance: validation of the HOW2 Benchmark Study. Am J Infect Control 2014 Jun;42(6):602-607. [doi: 10.1016/j.ajic.2014.02.020] [Medline: 24837110]

37. Diefenbacher S, Pfattheicher S, Keller J. On the role of habit in self-reported and observed hand hygiene behavior. Appl Psychol Health Well Being 2020 Mar 28;12(1):125-143. [doi: 10.1111/aphw.12176] [Medline: 31353823]

38. Armellino D, Hussain E, Schilling ME, Senicola W, Eichorn A, Dlugacz Y, et al. Using high-technology to enforce low-technology safety measures: the use of third-party remote video auditing and real-time feedback in healthcare. Clin Infect Dis 2012 Jan 01;54(1):1-7 [FREE Full text] [doi: 10.1093/cid/cir773] [Medline: 22109950]

39. Armellino D, Trivedi M, Law I, Singh N, Schilling ME, Hussain E, et al. Replicating changes in hand hygiene in a surgical intensive care unit with remote video auditing and feedback. Am J Infect Control 2013 Oct;41(10):925-927. [doi:

10.1016/j.ajic.2012.12.011] [Medline: 23489740]

40. Diefenbacher S, Sassenrath C, Tatzel J, Keller J. Evaluating healthcare workers' hand hygiene performance using first-person view video observation in a standardized patient-care scenario. Am J Infect Control 2020 May;48(5):496-502. [doi: 10.1016/j.ajic.2019.11.032] [Medline: 32334725]

41. Zhong C, Reibman AR, Cordoba HM, Deering AJ. Hand-hygiene activity recognition in egocentric video. In: Proceedings of the IEEE 21st International Workshop on Multimedia Signal Processing (MMSP). 2019 Presented at: IEEE 21st International Workshop on Multimedia Signal Processing (MMSP); Sept. 27-29, 2019; Kuala Lumpur, Malaysia. [doi: 10.1109/mmsp.2019.8901753]

42. Snoek J, Taati B, Eskin Y, Mihailidis A. Automatic segmentation of video to aid the study of faucet usability for older adults. In: Proceedings of the IEEE Computer Society Conference on Computer Vision and Pattern Recognition - Workshops. 2010 Presented at: IEEE Computer Society Conference on Computer Vision and Pattern Recognition - Workshops; June 13-18, 2010; San Francisco, CA, USA. [doi: 10.1109/cvprw.2010.5543266]

43. Awwad S, Tarvade S, Piccardi M, Gattas DJ. The use of privacy-protected computer vision to measure the quality of healthcare worker hand hygiene. Int J Qual Health Care 2019 Feb 01;31(1):36-42. [doi: 10.1093/intqhc/mzy099] [Medline: 29767747]

44. Arai A, Tanabe M, Nakamura A, Yamasaki D, Muraki Y, Kaneko T, et al. Utility of electronic hand hygiene counting devices for measuring physicians' hand hygiene adherence applied to outpatient settings. Am J Infect Control 2016 Dec 01;44(12):1481-1485 [FREE Full text] [doi: 10.1016/j.ajic.2016.08.002] [Medline: 27665030]

45. Asai T, Kanazawa A, Hayashi H, Minazuki A. Development of a system to raise awareness of hand hygiene in various environments. In: Proceedings of the International Conference on Signal-Image Technology \& Internet-Based Systems. 2013 Presented at: International Conference on Signal-Image Technology \& Internet-Based Systems; Dec. 2-5, 2013; Kyoto, Japan. [doi: 10.1109/sitis.2013.150]

46. Boyce JM, Cooper T, Dolan MJ. Evaluation of an electronic device for real-time measurement of alcohol-based hand rub use. Infect Control Hosp Epidemiol 2009 Nov 02;30(11):1090-1095. [doi: 10.1086/644756] [Medline: 19775238]

47. Cohen B, Murray M, Jia H, Jackson O, Saiman L, Neu N, et al. Is hand hygiene frequency associated with the onset of outbreaks in pediatric long-term care? Am J Infect Control 2016 Dec 01;44(12):1492-1494 [FREE Full text] [doi: 10.1016/j.ajic.2016.06.022] [Medline: 27566873]

48. Conway LJ, Riley L, Saiman L, Cohen B, Alper P, Larson EL. Implementation and impact of an automated group monitoring and feedback system to promote hand hygiene among health care personnel. Jt Comm J Qual Patient Saf 2014 Sep;40(9):408-417. [doi: 10.1016/s1553-7250(14)40053-9]

49. Macedo RC, Jacob EM, Silva VP, Santana EA, Souza AF, Gonçalves P, et al. Positive deviance: using a nurse call system to evaluate hand hygiene practices. Am J Infect Control 2012 Dec;40(10):946-950. [doi: 10.1016/j.ajic.2011.11.015] [Medline: 22418606]

50. Diefenbacher S, Fliss P, Tatzel J, Wenk J, Keller J. A quasi-randomized controlled before-after study using performance feedback and goal setting as elements of hand hygiene promotion. J Hosp Infect 2019 Apr;101(4):399-407. [doi: 10.1016/j.jhin.2019.02.001] [Medline: 30738912] 
51. Ellison RT, Barysauskas CM, Rundensteiner EA, Wang D, Barton B. A prospective controlled trial of an electronic hand hygiene reminder system. Open Forum Infect Dis 2015 Dec;2(4):ofv121 [FREE Full text] [doi: 10.1093/ofid/ofv121] [Medline: 26430698]

52. Galluzzi V, Herman T, Shumaker DJ, Macinga DR, Arbogast JW, Segre EM, et al. Electronic recognition of hand hygiene technique and duration. Infect Control Hosp Epidemiol 2014 Oct 10;35(10):1298-1300. [doi: 10.1086/678059] [Medline: 25203186]

53. Geilleit R, Hen ZQ, Chong CY, Loh AP, Pang NL, Peterson GM, et al. Feasibility of a real-time hand hygiene notification machine learning system in outpatient clinics. J Hosp Infect 2018 Oct;100(2):183-189. [doi: 10.1016/j.jhin.2018.04.004] [Medline: 29649558]

54. Helder OK, van Goudoever JB, Hop WC, Brug J, Kornelisse RF. Hand disinfection in a neonatal intensive care unit: continuous electronic monitoring over a one-year period. BMC Infect Dis 2012 Oct 08;12(1):248 [FREE Full text] [doi: 10.1186/1471-2334-12-248] [Medline: 23043639]

55. Kato H, Takeda R, Ideno Y, Suzuki T, Sano K, Nakamura K. Physicians' compliance for hand hygiene in medical outpatient clinics: automated hand-hygiene monitoring with touch sensor and wireless internet. Am J Infect Control 2021 Jan;49(1):50-54. [doi: 10.1016/j.ajic.2020.05.037] [Medline: 32512079]

56. Marra AR, Moura DF, Paes T, dos Santos OF, Edmond MB. Measuring rates of hand hygiene adherence in the intensive care setting: a comparative study of direct observation, product usage, and electronic counting devices. Infect Control Hosp Epidemiol 2010 Aug 02;31(8):796-801. [doi: 10.1086/653999] [Medline: 20565261]

57. Scheithauer S, Batzer B, Dangel M, Passweg J, Widmer A. Workload even affects hand hygiene in a highly trained and well-staffed setting: a prospective 365/7/24 observational study. J Hosp Infect 2017 Sep;97(1):11-16. [doi: 10.1016/j.jhin.2017.02.013] [Medline: 28389091]

58. Miyazaki K, Tobita H. SinkAmp: interactive sink to detect living habits for healthcare and quality of life. In: Proceedings of the 23rd International Conference on Intelligent User Interfaces Companion. 2018 Presented at: Proceedings of the 23rd International Conference on Intelligent User Interfaces Companion; March 7 - 11, 2018; Tokyo Japan p. 1-2. [doi: 10.1145/3180308.3180339]

59. Morgan DJ, Pineles L, Shardell M, Young A, Ellingson K, Jernigan JA, et al. Automated hand hygiene count devices may better measure compliance than human observation. Am J Infect Control 2012 Dec;40(10):955-959. [doi: 10.1016/j.ajic.2012.01.026] [Medline: 22633134]

60. Ram PK, Halder AK, Granger SP, Jones T, Hall P, Hitchcock D, et al. Is structured observation a valid technique to measure handwashing behavior? Use of acceleration sensors embedded in soap to assess reactivity to structured observation. Am $\mathrm{J}$ Trop Med Hyg 2010 Nov;83(5):1070-1076 [FREE Full text] [doi: 10.4269/ajtmh.2010.09-0763] [Medline: 21036840]

61. Sharma D, Thomas GW, Foster ED, Iacovelli J, Lea KM, Streit JA, et al. The precision of human-generated hand-hygiene observations: a comparison of human observation with an automated monitoring system. Infect Control Hosp Epidemiol 2012 Dec 02;33(12):1259-1261 [FREE Full text] [doi: 10.1086/668426] [Medline: 23143367]

62. Tobita H, Matsumoto M, Maida Y, Eguchi Y, Terada K. SinkNet: Interactive sink to detect living habits for healthcare and quality of life using private networks. In: Proceedings of the IEEE International Conference on Artificial Intelligence and Virtual Reality (AIVR). 2018 Presented at: IEEE International Conference on Artificial Intelligence and Virtual Reality (AIVR); Dec. 10-12, 2018; Taichung, Taiwan. [doi: 10.1109/aivr.2018.00020]

63. Uddin M, Salem A, Nam I, Nadeem T. Wearable sensing framework for human activity monitoring. In: Proceedings of the 2015 workshop on Wearable Systems and Applications`. 2015 Presented at: MobiSys'15: The 13th Annual International Conference on Mobile Systems, Applications, and Services; May 18, 2015; Florence Italy p. 21-26. [doi: $10.1145 / 2753509.2753513]$

64. Wright RL, Zillmer R, Biran A, Hall P, Sidibe M. Use of electronic loggers to measure changes in the rates of hand washing with soap in low-income urban households in India. PLoS One 2015 Jun 23;10(6):e0131187 [FREE Full text] [doi: 10.1371/journal.pone.0131187] [Medline: 26101886]

65. Zillmer R, Wright R, Bates S, Mahers I. A robust device for large-scale monitoring of bar soap usage in free-living conditions. Pers Ubiquit Comput 2014 Feb 1;18(8):2057-2064. [doi: 10.1007/s00779-014-0760-9]

66. Gaube S, Tsivrikos D, Dollinger D, Lermer E. How a smiley protects health: a pilot intervention to improve hand hygiene in hospitals by activating injunctive norms through emoticons. PLoS One 2018 May 21;13(5):e0197465 [FREE Full text] [doi: 10.1371/journal.pone.0197465] [Medline: 29782516]

67. Marra AR, Camargo TZ, Magnus TP, Blaya RP, Dos Santos G, Guastelli LR, et al. The use of real-time feedback via wireless technology to improve hand hygiene compliance. Am J Infect Control 2014 Jun;42(6):608-611. [doi: 10.1016/j.ajic.2014.02.006] [Medline: 24725515]

68. Galluzzi V, Herman T, Polgreen P. Hand hygiene duration and technique recognition using wrist-worn sensors. In: Proceedings of the 14th International Conference on Information Processing in Sensor Networks. 2015 Presented at: IPSN '15: The 14th International Conference on Information Processing in Sensor Networks; April 13 - 16, 2015 ; Seattle Washington p. 106-117. [doi: 10.1145/2737095.2737106]

69. Li H, Chawla S, Li R, Jain S, Abowd G, Starner T, et al. Wristwash: towards automatic handwashing assessment using a wrist-worn device. In: Proceedings of the 2018 ACM International Symposium on Wearable Computers. 2018 Presented 
at: UbiComp '18: The 2018 ACM International Joint Conference on Pervasive and Ubiquitous Computing; October 8 - 12 , 2018; Singapore p. 132-139. [doi: 10.1145/3267242.3267247]

70. Wijayasingha L, Lo B. A wearable sensing framework for improving personal and oral hygiene for people with developmental disabilities. In: Proceedings of the IEEE Wireless Health (WH). 2016 Presented at: IEEE Wireless Health (WH); Oct. 25-27, 2016; Bethesda, MD, USA. [doi: 10.1109/wh.2016.7764550]

71. Bal M, Abrishambaf R. A system for monitoring hand hygiene compliance based-on Internet-of-Things. In: Proceedings of the IEEE International Conference on Industrial Technology (ICIT). 2017 Presented at: IEEE International Conference on Industrial Technology (ICIT); March 22-25, 2017; Toronto, ON, Canada. [doi: 10.1109/icit.2017.7915560]

72. Baslyman M, Rezaee R, Amyot D, Mouttham A, Chreyh R, Geiger G, et al. Real-time and location-based hand hygiene monitoring and notification: proof-of-concept system and experimentation. Pers Ubiquit Comput 2015 Jun 16;19(3-4):667-688. [doi: 10.1007/s00779-015-0855-y]

73. Boudjema S, Dufour JC, Aladro AS, Desquerres I, Brouqui P. MediHandTrace: a tool for measuring and understanding hand hygiene adherence. Clin Microbiol Infect 2014 Jan;20(1):22-28 [FREE Full text] [doi: 10.1111/1469-0691.12471] [Medline: 24261513]

74. Boyce JM, Cooper T, Yin J, Li F, Arbogast JW. Challenges encountered and lessons learned during a trial of an electronic hand hygiene monitoring system. Am J Infect Control 2019 Dec;47(12):1443-1448. [doi: 10.1016/j.ajic.2019.05.019] [Medline: 31324492]

75. Brouqui P, Boudjema S, Soto Aladro A, Chabrière E, Florea O, Nguyen H, et al. New approaches to prevent healthcare-associated infection. Clin Infect Dis 2017 Aug 15;65(suppl_1):50-54. [doi: 10.1093/cid/cix433] [Medline: 28859352]

76. Decker AS, Cipriano GC, Tsouri G, Lavigne JE. Monitoring pharmacy student adherence to World Health Organization hand hygiene indications using radio frequency identification. Am J Pharm Educ 2016 Apr 25;80(3):51 [FREE Full text] [doi: 10.5688/ajpe80351] [Medline: 27170822]

77. Dyson J, Madeo M. Investigating the use of an electronic hand hygiene monitoring and prompt device: influence and acceptability. J Infect Prev 2017 Nov 04;18(6):278-287 [FREE Full text] [doi: 10.1177/1757177417714045] [Medline: 29344097]

78. Filho MA, Marra AR, Magnus TP, Rodrigues RD, Prado M, de Souza Santini TR, et al. Comparison of human and electronic observation for the measurement of compliance with hand hygiene. Am J Infect Control 2014 Nov;42(11):1188-1192. [doi: 10.1016/j.ajic.2014.07.031] [Medline: 25234045]

79. Fisher DA, Seetoh T, May-Lin HO, Viswanathan S, Toh Y, Yin WC, et al. Automated measures of hand hygiene compliance among healthcare workers using ultrasound: validation and a randomized controlled trial. Infect Control Hosp Epidemiol 2013 Sep 02;34(9):919-928. [doi: 10.1086/671738] [Medline: 23917905]

80. Fries J, Segre AM, Thomas G, Herman T, Ellingson K, Polgreen PM. Monitoring hand hygiene via human observers: how should we be sampling? Infect Control Hosp Epidemiol 2012 Jul 02;33(7):689-695 [FREE Full text] [doi: 10.1086/666346] [Medline: 22669230]

81. Herman T, Pemmaraju S, Segre AM, Polgreen PM, Curtis DE, Fries J, et al. Wireless applications for hospital epidemiology. In: Proceedings of the 1st ACM international workshop on Medical-grade wireless networks. 2009 Presented at: MobiHoc '09: The Tenth ACM International Symposium on Mobile Ad Hoc Networking and Computing; May 18, 2009; New Orleans Louisiana USA p. 45-50. [doi: 10.1145/1540373.1540384]

82. Hornbeck T, Naylor D, Segre AM, Thomas G, Herman T, Polgreen PM. Using sensor networks to study the effect of peripatetic healthcare workers on the spread of hospital-associated infections. J Infect Dis 2012 Nov 15;206(10):1549-1557 [FREE Full text] [doi: 10.1093/infdis/jis542] [Medline: 23045621]

83. Jain S, Mane S, Lopez J, Lie D, Dallas T, Dissanaike S, et al. A low-cost custom HF RFID system for hand washing compliance monitoring. In: Proceedings of the IEEE 8th International Conference on ASIC. 2009 Presented at: IEEE 8th International Conference on ASIC; Oct. 20-23, 2009; Changsha, China. [doi: 10.1109/asicon.2009.5351530]

84. Johnson R, Tsouri GR, Walsh E. Continuous and automated measuring of compliance of hand-hygiene procedures using finite state machines and RFID. IEEE Instrum Meas Mag 2012 Apr;15(2):8-12. [doi: 10.1109/mim.2012.6174572]

85. Karimpour N, Karaduman B, Ural A, Challengerl M, Dagdeviren O. IoT based hand hygiene compliance monitoring. In: Proceedings of the International Symposium on Networks, Computers and Communications (ISNCC). 2019 Presented at: International Symposium on Networks, Computers and Communications (ISNCC); June 18-20, 2019; Istanbul, Turkey. [doi: 10.1109/isncc.2019.8909151]

86. Levchenko AI, Boscart VM, Ibbett JP, Fernie GR. Distributed IR based technology to monitor hand hygiene of healthcare staff. In: Proceedings of the IEEE Toronto International Conference Science and Technology for Humanity (TIC-STH). 2009 Presented at: IEEE Toronto International Conference Science and Technology for Humanity (TIC-STH); Sept. 26-27, 2009; Toronto, ON, Canada. [doi: 10.1109/tic-sth.2009.5444496]

87. Levchenko AI, Boscart VM, Fernie GR. Automated monitoring: a potential solution for achieving sustainable improvement in hand hygiene practices. Comput Inform Nurs 2014 Aug;32(8):397-403. [doi: 10.1097/CIN.0000000000000067] [Medline: 24859431] 
88. Levchenko AI, Boscart VM, Fernie GR. Hand hygiene monitoring and real-time prompting system. In: Proceedings of the IEEE International Systems Conference SysCon 2012. 2012 Presented at: IEEE International Systems Conference SysCon 2012; March 19-22, 2012; Vancouver, BC, Canada. [doi: 10.1109/syscon.2012.6189435]

89. Levchenko AI, Boscart VM, Fernie GR. The effect of automated monitoring and real-time prompting on nurses' hand hygiene performance. Comput Inform Nurs 2013 Oct;31(10):498-504. [doi: 10.1097/01.NCN.0000432124.53902.1d] [Medline: 23924823]

90. Levin PD, Razon R, Schwartz C, Avidan A, Sprung CL, Moses AE, et al. Obstacles to the successful introduction of an electronic hand hygiene monitoring system, a cohort observational study. Antimicrob Resist Infect Control 2019 Feb 22;8(1):43 [FREE Full text] [doi: 10.1186/s13756-019-0498-2] [Medline: 30834111]

91. Marques R, Gregório J, Pinheiro F, Póvoa P, da Silva MM, Lapão LV. How can information systems provide support to nurses' hand hygiene performance? Using gamification and indoor location to improve hand hygiene awareness and reduce hospital infections. BMC Med Inform Decis Mak 2017 Jan 31;17(1):15 [FREE Full text] [doi: 10.1186/s12911-017-0410-z] [Medline: 28143613]

92. Polgreen PM, Hlady CS, Severson MA, Segre AM, Herman T. Method for automated monitoring of hand hygiene adherence without radio-frequency identification. Infect Control Hosp Epidemiol 2010 Dec 02;31(12):1294-1297 [FREE Full text] [doi: 10.1086/657333] [Medline: 20973724]

93. Meydanci MA, Adali C, Ertas M, Dizbay M, Akan A. RFID based hand hygiene compliance monitoring station. In: IEEE International Conference on Control System, Computing and Engineering. 2013 Presented at: IEEE International Conference on Control System, Computing and Engineering; Nov. 29 - Dec. 1, 2013; Penang, Malaysia. [doi: 10.1109/iccsce.2013.6720030]

94. Misra P, Rajaraman V, Aishwarya SN, Dwivedi B, Warrior J. CleanHands: an integrated monitoring system for control of hospital acquired infections. In: Proceedings of the 14th International Conference on Information Processing in Sensor Networks. 2015 Presented at: IPSN '15: The 14th International Conference on Information Processing in Sensor Networks; April 13 - 16, 2015; Seattle Washington p. 348-349. [doi: 10.1145/2737095.2742928]

95. Monsalve M, Pemmaraju S, Polgreen PM. Interactions in an intensive care unit: experiences pre-processing sensor network data. In: Proceedings of the 4th Conference on Wireless Health. 2013 Presented at: WH '13: Wireless Health 2013; November 1 - 3, 2013; Baltimore Maryland p. 1-8. [doi: 10.1145/2534088.2534105]

96. Monsalve MN, Pemmaraju SV, Thomas GW, Herman T, Segre AM, Polgreen PM. Do peer effects improve hand hygiene adherence among healthcare workers? Infect Control Hosp Epidemiol 2014 Oct 10;35(10):1277-1285 [FREE Full text] [doi: 10.1086/678068] [Medline: 25203182]

97. Pleteršek A, Sok M, Trontelj J. Monitoring, control and diagnostics using RFID infrastructure. J Med Syst 2012 Dec 22;36(6):3733-3739. [doi: 10.1007/s10916-012-9846-y] [Medline: 22438102]

98. Pong S, Holliday P, Fernie G. Effect of intermittent deployment of an electronic monitoring system on hand hygiene behaviors in healthcare workers. Am J Infect Control 2019 Apr;47(4):376-380 [FREE Full text] [doi:

10.1016/j.ajic.2018.08.029] [Medline: 30502113]

99. Radhakrishna K, Waghmare A, Ekstrand M, Raj T, Selvam S, Sreerama SM, et al. Real-time feedback for improving compliance to hand sanitization among healthcare workers in an open layout ICU using radiofrequency identification. $\mathrm{J}$ Med Syst 2015 Jun 10;39(6):68 [FREE Full text] [doi: 10.1007/s10916-015-0251-1] [Medline: 25957165]

100. Srigley JA, Furness CD, Baker GR, Gardam M. Quantification of the Hawthorne effect in hand hygiene compliance monitoring using an electronic monitoring system: a retrospective cohort study. BMJ Qual Saf 2014 Dec 07;23(12):974-980 [FREE Full text] [doi: 10.1136/bmjqs-2014-003080] [Medline: 25002555]

101. Wan Y, Stombaugh TS, Wang N. Human-subject tracking and localization for a hand hygiene monitoring system. In: Proceedings of the Ubiquitous Positioning Indoor Navigation and Location Based Service (UPINLBS). 2014 Presented at: Ubiquitous Positioning Indoor Navigation and Location Based Service (UPINLBS); Nov. 20-21, 2014; Corpus Christi, TX, USA. [doi: 10.1109/upinlbs.2014.7033719]

102. Camilus S, Lee YM. Automated hand hygiene compliance monitoring. In: Proceedings of the 2020 2nd International Conference on Image, Video and Signal Processing. 2020 Presented at: IVSP '20: 2020 2nd International Conference on Image, Video and Signal Processing; March 20 - 22, 2020; Singapore p. 64-69. [doi: 10.1145/3388818.3388824]

103. Lacey G, Zhou J, Li X, Craven C, Gush C. The impact of automatic video auditing with real-time feedback on the quality and quantity of handwash events in a hospital setting. Am J Infect Control 2020 Feb;48(2):162-166 [FREE Full text] [doi: 10.1016/j.ajic.2019.06.015] [Medline: $\underline{31358419]}$

104. Zhong H, Kanhere SS, Chou CT. WashInDepth: Lightweight hand wash monitor using depth sensor. In: Proceedings of the 13th International Conference on Mobile and Ubiquitous Systems: Computing, Networking and Services. 2016 Presented at: MOBIQUITOUS 2016: Computing, Networking and Services; November 28 - December 1, 2016; Hiroshima Japan p. 28-37. [doi: 10.1145/2994374.2994386]

105. Khamis A, Kusy B, Chou CT, McLaws M, Hu W. Poster abstract: a weakly supervised tracking of hand hygiene technique. In: Proceedings of the 19th ACM/IEEE International Conference on Information Processing in Sensor Networks (IPSN). 2020 Presented at: 19th ACM/IEEE International Conference on Information Processing in Sensor Networks (IPSN); April 21-24, 2020; Sydney, NSW, Australia. [doi: 10.1109/ipsn48710.2020.00-21] 
106. Khan A, Nausheen S. Compliance of surgical hand washing before surgery: role of remote video surveillance. J Pak Med Assoc 2017 Jan;67(1):92-96 [FREE Full text] [Medline: 28065962]

107. Banerjee A, Amperyani VN, Gupta SK. Hand hygiene compliance checking system with explainable feedback. In: Proceedings of the 6th ACM Workshop on Wearable Systems and Applications. 2020 Presented at: MobiSys '20: The 18th Annual International Conference on Mobile Systems, Applications, and Services; June 19, 2020; Toronto Ontario Canada p. $34-36$. [doi: $10.1145 / 3396870.3400015]$

108. Kutafina E, Laukamp D, Jonas SM. Wearable sensors in medical education: supporting hand hygiene training with a forearm EMG. Stud Health Technol Inform 2015;211:286-291. [Medline: 25980884]

109. Kutafina E, Laukamp D, Bettermann R, Schroeder U, Jonas SM. Wearable sensors for elearning of manual tasks: using forearm EMG in hand hygiene training. Sensors (Basel) 2016 Aug 03;16(8):1221 [FREE Full text] [doi: 10.3390/s16081221] [Medline: 27527167]

110. Wang C, Sarsenbayeva Z, Chen X, Dingler T, Goncalves J, Kostakos V. Accurate measurement of handwash quality using sensor armbands: instrument validation study. JMIR Mhealth Uhealth 2020 Mar 26;8(3):e17001 [FREE Full text] [doi: 10.2196/17001] [Medline: $\underline{32213469}$ ]

111. Pellegrino R, Crandall PG, Seo HS. Using olfaction and unpleasant reminders to reduce the intention-behavior gap in hand washing. Sci Rep 2016 Jan 06;6(1):18890 [FREE Full text] [doi: 10.1038/srep18890] [Medline: 26732033]

112. Srisomboon K, Malathum K, Skuntaniyom S, Duangthongkham J, Phanthuna N. Hand hygiene auditing algorithm using image processing for hand hygiene evaluation machine. In: Proceedings of the 16th International Conference on Electrical Engineering/Electronics, Computer, Telecommunications and Information Technology (ECTI-CON). 2019 Presented at: 16th International Conference on Electrical Engineering/Electronics, Computer, Telecommunications and Information Technology (ECTI-CON); July 10-13, 2019; Pattaya, Thailand. [doi: 10.1109/ecti-con47248.2019.8955358]

113. Szilágyi L, Lehotsky A, Nagy M, Haidegger T, Benyó B, Benyó Z. Stery-hand: a new device to support hand disinfection. In: Proceedings of the Annual International Conference of the IEEE Engineering in Medicine and Biology. 2010 Presented at: Annual International Conference of the IEEE Engineering in Medicine and Biology; Aug. 31 - Sept. 4, 2010; Buenos Aires, Argentina. [doi: 10.1109/iembs.2010.5626377]

114. Yamamoto K, Miyanaga K, Miyahara H, Yoshii M, Kinoshita F, Touyama H. Toward the evaluation of handwashing skills based on image processing. In: Proceedings of the Joint 10th International Conference on Soft Computing and Intelligent Systems (SCIS) and 19th International Symposium on Advanced Intelligent Systems (ISIS). 2018 Presented at: Joint 10th International Conference on Soft Computing and Intelligent Systems (SCIS) and 19th International Symposium on Advanced Intelligent Systems (ISIS); Dec. 5-8, 2018; Toyama, Japan. [doi: 10.1109/scis-isis.2018.00141]

115. Yamamoto K, Yoshii M, Kinoshita F, Touyama H. Classification vs regression by CNN for handwashing skills evaluations in nursing education. In: International Conference on Artificial Intelligence in Information and Communication (ICAIIC). 2020 Presented at: International Conference on Artificial Intelligence in Information and Communication (ICAIIC); Feb. 19-21, 2020; Fukuoka, Japan. [doi: 10.1109/icaiic48513.2020.9064974]

116. Naim F, Jaafar R, Arshad NW, Hamid R, Razali M. Unclean hand detection machine using vision sensor. In: Proceedings of the Saudi International Electronics, Communications and Photonics Conference. 2013 Presented at: Saudi International Electronics, Communications and Photonics Conference; April 27-30, 2013; Riyadh, Saudi Arabia. [doi: 10.1109/siecpc.2013.6550750]

117. Hlady CS, Severson MA, Segre AM, Polgreen PM. A mobile handheld computing application for recording hand hygiene observations. Infect Control Hosp Epidemiol 2010 Sep 02;31(9):975-977 [FREE Full text] [doi: 10.1086/655834] [Medline: 20636134]

118. Kinney P. ZigBee Technology: wireless control that simply works. Commun Des Conf. 2003. URL: https://www.itk.ntnu.no/ fag/TTK4545/TTK2/PDF/ZigBee\%20Technology\%20-\%20Wireless\%20control\%20that\%20simply\%20works.pdf [accessed 2021-10-22]

119. Goroncy-Bermes P, Koburger T, Meyer B. Impact of the amount of hand rub applied in hygienic hand disinfection on the reduction of microbial counts on hands. J Hosp Infect 2010 Mar;74(3):212-218. [doi: 10.1016/j.jhin.2009.09.018] [Medline: $\underline{20061058]}$

120. Lehotsky A, Szilágyi L, Bánsághi S, Szerémy P, Wéber G, Haidegger T. Towards objective hand hygiene technique assessment: validation of the ultraviolet-dye-based hand-rubbing quality assessment procedure. J Hosp Infect 2017 Sep;97(1):26-29. [doi: 10.1016/j.jhin.2017.05.022] [Medline: 28579470]

121. Conway LJ. Challenges in implementing electronic hand hygiene monitoring systems. Am J Infect Control 2016 May 02;44(5 Suppl):7-12. [doi: 10.1016/j.ajic.2015.11.031] [Medline: 27131139]

122. Ellingson K, Polgreen PM, Schneider A, Shinkunas L, Kaldjian LC, Wright D, et al. Healthcare personnel perceptions of hand hygiene monitoring technology. Infect Control Hosp Epidemiol 2011 Nov 02;32(11):1091-1096. [doi: 10.1086/662179] [Medline: 22011536]

123. Gu Y, Lo A, Niemegeers I. A survey of indoor positioning systems for wireless personal networks. IEEE Commun Surv Tutorials 2009;11(1):13-32. [doi: 10.1109/surv.2009.090103] 
124. Fung ML, Chen MZ, Chen YH. Sensor fusion: A review of methods and applications. In: Proceedings of the 29th Chinese Control And Decision Conference (CCDC). 2017 Presented at: 29th Chinese Control And Decision Conference (CCDC); May 28-30, 2017; Chongqing, China. [doi: 10.1109/ccdc.2017.7979175]

125. Wang C, Sarsenbayeva Z, Luo C, Goncalves J, Kostakos V. Improving wearable sensor data quality using context markers. In: Proceedings of the 2019 ACM International Joint Conference on Pervasive and Ubiquitous Computing and Proceedings of the 2019 ACM International Symposium on Wearable Computers. 2019 Presented at: UbiComp '19: The 2019 ACM International Joint Conference on Pervasive and Ubiquitous Computing; September 9 - 13, 2019; London United Kingdom p. 598-601. [doi: 10.1145/3341162.3349334]

126. Bannach D, Amft O, Lukowicz P. Automatic event-based synchronization of multimodal data streams from wearable and ambient sensors. In: Barnaghi P, Moessner K, Presser M, Meissner S, editors. Smart Sensing and Context. Berlin, Heidelberg: Springer; 2009:135-148.

127. Palmore T, Henderson DK. Big brother is washing... Video surveillance for hand hygiene adherence, through the lenses of efficacy and privacy. Clin Infect Dis 2012 Jan 01;54(1):8-9 [FREE Full text] [doi: 10.1093/cid/cir781] [Medline: 22109949]

128. Cilliers L. Wearable devices in healthcare: privacy and information security issues. Health Inf Manag 2020 May 30;49(2-3):150-156. [doi: 10.1177/1833358319851684] [Medline: 31146589]

129. American Conference of Governmental Industrial Hygienists. TLVs and BEIs : Threshold Limit Values for Chemical Substances and Physical Agents and Biological Exposure Indices. Cincinnati, OH: ACGIH Worldwide; 2016.

130. Zarb P, Coignard B, Griskeviciene J, Muller A, Vankerckhoven V, Weist K, National Contact Points for the ECDC pilot point prevalence survey, Hospital Contact Points for the ECDC pilot point prevalence survey. The European Centre for Disease Prevention and Control (ECDC) pilot point prevalence survey of healthcare-associated infections and antimicrobial use. Euro Surveill 2012 Nov 15;17(46):20316 [FREE Full text] [doi: 10.2807/ese.17.46.20316-en] [Medline: 23171822]

131. Trick WE, Vernon MO, Hayes RA, Nathan C, Rice TW, Peterson BJ, et al. Impact of ring wearing on hand contamination and comparison of hand hygiene agents in a hospital. Clin Infect Dis 2003 Jun 01;36(11):1383-1390. [doi: 10.1086/374852] [Medline: 12766832]

132. Bassen HI. Radiofrequency interference with medical devices. A technical information statement. IEEE Eng Med Biol Mag 1998;17(3):111-114. [Medline: 9604711]

133. Badizadegan ND, Greenberg S, Lawrence H, Badizadegan K. Radiofrequency interference in the clinical laboratory. Am J Clin Pathol 2019 Apr 02;151(5):522-528 [FREE Full text] [doi: 10.1093/ajcp/aqy174] [Medline: 30668626]

134. van der Togt R, van Lieshout EJ, Hensbroek R, Beinat E, Binnekade JM, Bakker PJ. Electromagnetic interference from radio frequency identification inducing potentially hazardous incidents in critical care medical equipment. J Am Med Assoc 2008 Jun 25;299(24):2884-2890. [doi: 10.1001/jama.299.24.2884] [Medline: 18577733]

135. Li X, Zhang D, Lv Q, Xiong J, Li S, Zhang Y, et al. IndoTrack: Device-free indoor human tracking with commodity Wi-Fi. Proc ACM Interact Mob Wearable Ubiquitous Technol 2017 Sep 11;1(3):1-22. [doi: 10.1145/3130940]

136. Matteson DS, James NA. A nonparametric approach for multiple change point analysis of multivariate data. J Am Stat Assoc 2014 Mar 19;109(505):334-345. [doi: 10.1080/01621459.2013.849605]

137. Fasching J, Walczak N, Bernstein GA, Hadjiyanni T, Cullen K, Morellas V, et al. Automated coding of activity videos from an OCD study. In: Proceedings of the IEEE International Conference on Robotics and Automation (ICRA). 2016 Presented at: IEEE International Conference on Robotics and Automation (ICRA); May 16-21, 2016; Stockholm, Sweden. [doi: $10.1109 /$ icra.2016.7487783]

138. Ashraf A, Taati B. Automated video analysis of handwashing behavior as a potential marker of cognitive health in older adults. IEEE J Biomed Health Inform 2016 Mar;20(2):682-690. [doi: 10.1109/jbhi.2015.2413358]

139. Barnes S, Golden B, Wasil E, Furuno J, Harris A. An application of factorial design to compare the relative effectiveness of hospital infection control measures. In: Proceedings of the 2011 Winter Simulation Conference (WSC). 2011 Presented at: Winter Simulation Conference (WSC); Dec. 11-14, 2011; Phoenix, AZ, USA. [doi: 10.1109/wsc.2011.6147849]

\author{
Abbreviations \\ BLE: Bluetooth low energy \\ HAI: health care-associated infections \\ HCW: health care worker \\ IMU: inertial measurement unit \\ LED: light-emitting diode \\ PRISMA: Preferred Reporting Items for Systematic Reviews and Meta-Analyses \\ RFI: radio-frequency interference \\ RFID: radio-frequency identification \\ RGB: red green blue \\ RTLS: real-time locating system \\ sEMG: surface electromyography \\ WHO: World Health Organization
}




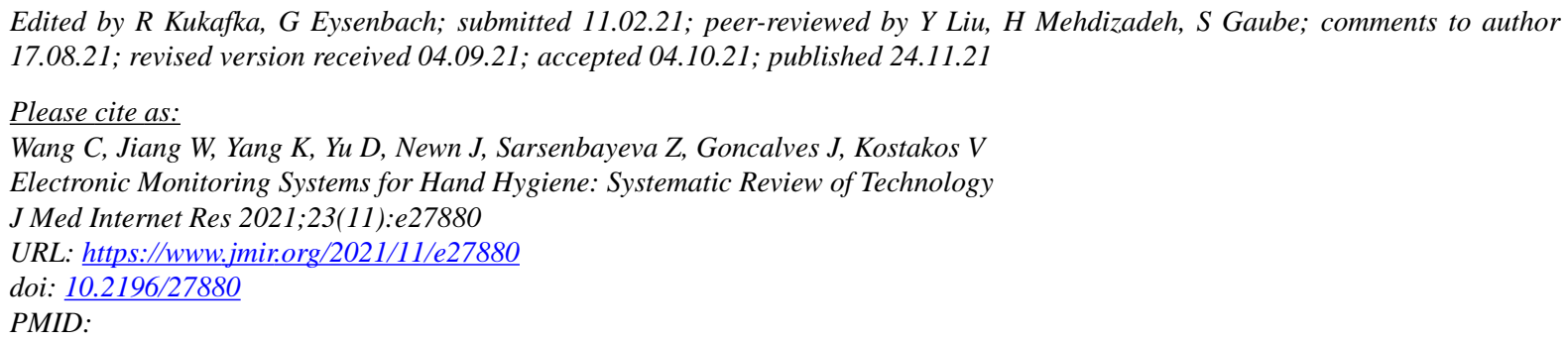

(C) Chaofan Wang, Weiwei Jiang, Kangning Yang, Difeng Yu, Joshua Newn, Zhanna Sarsenbayeva, Jorge Goncalves, Vassilis Kostakos. Originally published in the Journal of Medical Internet Research (https://www.jmir.org), 24.11.2021. This is an open-access article distributed under the terms of the Creative Commons Attribution License (https://creativecommons.org/licenses/by/4.0/), which permits unrestricted use, distribution, and reproduction in any medium, provided the original work, first published in the Journal of Medical Internet Research, is properly cited. The complete bibliographic information, a link to the original publication on https://www.jmir.org/, as well as this copyright and license information must be included. 